Article

\title{
Independent Assessment of Sentinel-3A Wet Tropospheric Correction over the Open and Coastal Ocean
}

\author{
Maria Joana Fernandes $1,2, *$ (D) and Clara Lázaro 1,2 (D) \\ 1 Faculdade de Ciências, Universidade do Porto, 4169-007 Porto, Portugal; clazaro@fc.up.pt \\ 2 Centro Interdisciplinar de Investigação Marinha e Ambiental (CIIMAR/CIMAR), Universidade do Porto, \\ 4050-123 Porto, Portugal \\ * Correspondence: mjfernan@fc.up.pt; Tel.: +351-220-402-452
}

Received: 25 January 2018; Accepted: 14 March 2018; Published: 20 March 2018

\begin{abstract}
Launched on 16 February 2016, Sentinel-3A (S3A) carries a two-band microwave radiometer (MWR) similar to that of Envisat, and is aimed at the precise retrieval of the wet tropospheric correction (WTC) through collocated measurements using the Synthetic Aperture Radar Altimeter (SRAL) instrument. This study aims at presenting an independent assessment of the WTC derived from the S3A MWR over the open and coastal ocean. Comparisons with other four MWRs show Root Mean Square (RMS) differences (cm) of S3A with respect to these sensors of 1.0 (Global Precipitation Measurement (GPM) Microwave Imager, GMI), 1.2 (Jason-2), 1.3 (Jason-3), and 1.5 (Satellite with ARgos and ALtika (SARAL)). The linear fit with respect to these MWR shows scale factors close to 1 and small offsets, indicating a good agreement between all these sensors. In spite of the short analysis period of 10 months, a stable temporal evolution of the S3A WTC has been observed. In line with the similar two-band instruments aboard previous European Space Agency (ESA) altimetric missions, strong ice and land contamination can be observed, the latter mainly found up to $20-25 \mathrm{~km}$ from the coast. Comparisons with the European Centre for Medium-Range Weather Forecasts (ECMWF) and an independent WTC derived only from third party data are also shown, indicating good overall performance. However, improvements in both the retrieval algorithm and screening of invalid MWR observations are desirable to achieve the quality of the equivalent WTC from Jason-3. The outcome of this study is a deeper knowledge of the measurement capabilities and limitations of the type of MWR aboard S3A and of the present WTC retrieval algorithms.
\end{abstract}

Keywords: Sentinel-3; satellite altimetry; microwave radiometer; wet tropospheric correction; wet path delay; sensor calibration

\section{Introduction}

Starting with European Remote Sensing 1 (ERS-1) in 1991 and TOPography Experiment (TOPEX)/Poseidon in 1992, satellite missions carrying radar altimeters have resulted in invaluable continuous measurements being obtained over the ocean, ice, rivers and lakes for more than 25 years. This has been made possible through the joint effort of various space agencies: the European Space Agency (ESA), the Centre National d'Études Spatiales (CNES), European Organisation for the Exploitation of Meteorological Satellites (EUMETSAT), the National Aeronautics and Space Administration (NASA), the Jet Propulsion Laboratory (JPL), the National Oceanic and Atmospheric Administration (NOAA), and the Indian Space Research Organization (ISRO). ESA supported the 35-day repeat missions ERS-1 (1991), ERS-2 (1995), and Envisat (2002), the geodetic mission CryoSat-2 (2010), and more recently, the 27-day repeat mission Sentinel-3A (2016), the latter in collaboration with EUMETSAT. Satellite with ARgos and ALtika (SARAL), a 35-day mission follow-up of Envisat, 
is a joint effort between the CNES and ISRO. Partly or in collaboration, NASA, NOAA, JPL, CNES, and EUMETSAT have been responsible for the so-called reference 10-day repeat missions: TOPEX/Poseidon (1991), Jason-1 (2002), Jason-2 (2008), and Jason-3 (2016) [1]. For a detailed and update review of satellite altimetry, see e.g., [2].

These missions have been designed to provide complementary spatial and temporal resolutions, allowing e.g., a better characterisation of the mesoscale oceanic circulation [3,4], the determination of accurate global and regional sea level trends [5-9], and unprecedented observations over river, lakes and reservoirs $[10,11]$ as well as ice surfaces [12].

Satellite altimetry allows the determination of the height of e.g., the sea or lake surface above a reference ellipsoid by means of the following equation [13]:

$$
h=H-R=H-R_{o b s}-\Delta R
$$

where $H$ is the spacecraft height above a reference ellipsoid provided by precise orbit determination, referred to as an International Terrestrial Reference Frame, $R_{o b s}$ is the measured altimeter range corrected for all instrument effects, and $R$ is the corresponding range corrected for all instrument, range, and geophysical effects. The term $\Delta R$ includes all corrections that need to be applied to the observed range due to the signal propagation delay through the atmosphere, its interaction with the sea surface and terms related with specific geophysical phenomena being given by Equation (2):

$$
\Delta R=\Delta R_{\text {dry }}+\Delta R_{\text {wet }}+\Delta R_{\text {iono }}+\Delta R_{S S B}+\Delta R_{\text {tides }}+\Delta R_{D A C}
$$

The first four terms in Equation (2) are the range corrections, accounting for the interaction of the altimeter radar signal with the atmosphere (dry, wet and ionospheric corrections) and with the sea surface (sea state bias). The last two terms refer to geophysical phenomena, dynamic atmospheric correction, and tides (ocean, load, solid earth and pole tides), which should be removed if they are not part of the signals of interest. A detailed description of the range and geophysical corrections can be found e.g., in $[13,14]$.

Equation (1) evidences that the determination of an accurate surface height requires the knowledge of the spacecraft orbit, the range measurement, and of all correction terms in Equation (2) with the same accuracy. Amidst these terms is the wet tropospheric correction (WTC), due to the water vapour and liquid water content in the atmosphere. Since these variables have large space-time variability, if not properly modelled, the WTC is one of the major sources of uncertainty in many satellite altimetry applications $[13,15,16]$.

Due to its variability, the most precise way to account for the WTC in satellite altimetry is by means of collocated measurements from a microwave radiometer (MWR), obtained on the same spacecraft. Two main types of radiometers have been deployed on the altimeter satellites: three-band radiometers on board the reference missions and two-band radiometers on all ESA missions and SARAL. Over the open ocean they provide accurate WTC retrievals within $1 \mathrm{~cm} \mathrm{[17].}$

The algorithms adopted in the WTC retrieval from the measured brightness temperatures (TBs) in the various spectral bands have been designed for the open ocean, assuming a constant ocean emissivity. In the presence of other surfaces such as land or ice, the measurements lay outside the predicted validity interval and the observations become unusable. Moreover, these instruments possess large footprints from 10 to $40 \mathrm{~km}$ depending on the frequency $[18,19]$. Therefore, in the coastal regions they sense land well before the altimeter, originating bands of invalid measurements around the coastline of a width of 10-40 km. In recent years, several methods have been developed to improve the MWR-derived WTC in the coastal zones, extending the validity of the correction up to the coast. An overview of these methods is given in [16].

Building directly on the proven heritage of ERS-1, ERS-2, and Envisat, launched on 16 February 2016, Sentinel-3A (S3A) carries a suite of innovative instruments that include [20]: (1) the Sea and Land Surface Temperature Radiometer (SLSTR) based on Envisat's Advanced Along Track 
Scanning Radiometer (AATSR), to determine global sea surface temperatures to an accuracy of better than $0.3 \mathrm{~K}$; the Ocean and Land Colour Instrument (OLCI), based on Envisat's Medium Resolution Imaging Spectrometer (MERIS), with 21 bands, (compared to 15 bands on MERIS), a design optimised to minimise Sun-glint, and a resolution of $300 \mathrm{~m}$ over all surfaces; a dual-frequency (Ku and C-band) advanced Synthetic Aperture Radar Altimeter (SRAL) developed from Envisat RA-2, CryoSat Synthetic Aperture Interferometric Radar Altimeter (SIRAL) and Jason-2/Poseidon-3, providing accurate surface topography measurements; and a microwave radiometer for accurate measurement of the wet pat delay of the SRAL observations [20].

SRAL and the MWR constitute the topography package, providing accurate measurements of sea surface height, significant wave height, and wind speed, essential for ocean forecasting systems and climate monitoring. Accurate SRAL measurements also extend to sea-ice, ice sheets, rivers, and lakes. Being the first altimeter mission to operate, globally, a radar altimeter in the SAR closed burst mode, with an improved along track resolution of about $300 \mathrm{~m}$ [21], Sentinel-3A is a pioneer and challenging mission in many aspects, pushing the experts of the various fields to the limit to tune the retrieval algorithms to its instruments and exploit the derived geophysical parameters.

As mentioned above, amongst its suite of instruments, Sentinel-3A carries a dual channel (23.8- $\mathrm{GHz}$ and $36.5-\mathrm{GHz})$ microwave radiometer aiming at the retrieval of the wet path delay, which provides important support for the quality of the SRAL measurements. Due to their instrumental characteristics and retrieval algorithms, the two-band MWRs deployed on ESA altimeter missions are known for their good performance in the open ocean [22]. However, when they approach the coast, the retrieval algorithm, which was designed for surfaces with ocean emissivity, generates very noisy values, as the footprint encounters surfaces with different levels of emissivity. The same happens at high latitudes in regions covered with ice [23,24].

This work aims at performing an independent assessment of S3A MWR-based WTC, in the open and coastal ocean, in support of S3A data improvement and exploitation.

The validation is performed by means of comparisons with independent data sets namely: wet path delays derived from the Global Precipitation Measurement (GPM) Microwave Imager (GMI); Global Navigation Satellite System (GNSS)-derived path delays determined at coastal stations; and wet path delays from the MWR on board Jason-2 (J2), Jason-3 (J3), and SARAL/AltiKa. In addition, the overall along-track performance is compared against independent estimates obtained from the GNSS-derived Path Delay Plus (GPD+) algorithm [24] and from atmospheric models. From this thorough analysis, a deeper knowledge of the measurement capabilities and limitations of the dual-frequency radiometer aboard S3A and of the present WTC retrieval algorithms is expected.

This paper is organised in five sections. Section 2 describes the data sets and the methodology used in the S3A WTC assessment. Section 3 describes the results obtained with the various datasets. Finally, Sections 4 and 5 present the discussions of the results and conclusions, respectively.

\section{Dataset Description}

\subsection{Sentinel-3 Data and the Radar Altimeter Database System (RADS)}

Sentinel-3A flies in a near-polar Sun-synchronous orbit with a Local Time of the Descending Node (LTDN) at 10:00 h. It has a high inclination of $98.65^{\circ}$, altitude of about $814.5 \mathrm{~km}$, a 27 -day repeat cycle (385 orbits per cycle), and 104-km inter-track spacing at the equator [20]. Sentinel-3B will be on a similar orbit, with an $180^{\circ}$ phase difference, the two satellites ensuring twice the spatial and temporal coverage.

The Sentinel-3 data used in this study are from the Sentinel-3 Surface Topography Mission (STM) Level-2 Non-Time Critical (NTC) products from the so-called "Spring 2017 Reprocessing Campaign" [25,26]. The product reference is SRAL/MWR L2 Instrument Processing Facility (IPF) (SM-2): version 06.07 from Processing Baseline 2.15. These data have been available in the Radar Altimeter Database System (RADS, http:/ / rads.tudelft.nl/rads/rads.shtml) [27] as reprocessed version 
1 (rep1), since mid-August 2017. In addition to the native S3A products, the website includes the orbit and state-of-the-art range and geophysical corrections present in RADS for all other altimeter missions. The data span approximately 10 months, from 15 June 2016 (cycle 05) to 15 April 2017 (cycle 16).

As mentioned above, Sentinel-3A MWR operates in two frequencies. The first, located at a water vapour absorption line $(23.8 \mathrm{GHz})$, is the primary water vapour sensing frequency; the second $(36.5 \mathrm{GHz})$ is an atmospheric window sensitive to surface emissivity and to cloud liquid water. In the dual-frequency microwave radiometers, which do not include any low frequency channel, the effect of surface roughness is often taken into account through the altimeter-derived wind speed or the backscatter coefficient.

The relation between the measured brightness temperatures of the various MWR channels and the wet path delay (WPD) or WTC has been empirically established by means of statistical regression methods. Two main types of algorithms have been used in the retrieval of the WTC from the TB of the various MWR channels: (1) a parametric log-linear algorithm adopted in the reference missions [17]; and (2) a neural network algorithm first developed for Envisat, later used in SARAL/AltiKa and Sentinel-3 [28].

The function adopted in the retrieval of the WPD from the MWR brightness temperatures is usually derived from TB simulations, obtained from a database of atmospheric and sea-surface scenes using a radiative transfer model. Several databases can be used. Traditionally, in the ESA missions the database is built from European Centre for Medium-Range Weather Forecasts (ECMWF) analyses, while in the reference missions, it is usually built from radiosonde observations (for the atmospheric profiles) and from microwave imaging radiometers such as the Special Sensor Microwave Imager (SSM/I), the SSM/I Sounder (SSM/IS), or the Advanced Very High Resolution Radiometer (to provide sea-surface parameters) [29]. In summary, a WPD retrieval algorithm consists in the empirical establishment of the inverse function to get the WPD from the simulated TB.

In [29], the parametric log-linear algorithm is compared with the neural network formalism. These authors also analyse the advantages of the three-band MWR flying in the reference missions versus the two-band MWR on board the ESA missions, as well as how well additional parameters such as the backscatter coefficient can replace the missing third channel in the ESA missions.

The MWR-derived WTC present in this product has been computed by a neural network algorithm based on five inputs [30]: brightness temperatures at $23.8 \mathrm{GHz}$ and $36.5 \mathrm{GHz}, \mathrm{Ku}$-band ocean backscatter coefficient (not corrected for the atmospheric attenuation), sea surface temperature (four seasonal tables, $2^{\circ}$ resolution), and the lapse rate (decreasing rate of atmospheric temperature with altitude, from a climatological table, $1^{\circ}$ resolution) [30]. This algorithm is an evolution of the one developed for Envisat that only used the first three inputs described above [28].

The S3A products also include composite wet tropospheric correction [30], based on both radiometer and model-based corrections over areas where the radiometer WTC is missing or invalid due to the proximity of land (coastal areas and/or radiometer gaps in open oceans) [30,31]. A first assessment of this correction is also performed.

In the sea level anomaly (SLA) variance analyses performed in Section 3, S3A SRAL data and all required range and geophysical corrections to compute SLA were extracted from RADS.

\subsection{The Global Precipitation Measurement (GPM) Microwave Imager (GMI)}

The GMI is a dual-polarization, multi-channel, conical-scanning, passive microwave imaging radiometer on board the GPM satellite, launched on 27 February 2014. GPM has a non-Sun-synchronous orbit, at a mean altitude of $407 \mathrm{~km}$ and inclination of $65^{\circ}$, covering the latitude band between $\pm 65^{\circ}$, allowing a full sampling of the Earth approximately every 2 weeks. The orbit plane completes half $\left(180^{\circ}\right)$ a rotation relative to the Sun every 41.1 days. The spacecraft undergoes yaw manoeuvres every $\sim 40$ days to compensate for the Sun's changing position and prevent the side of the spacecraft facing the Sun from overheating [32]. 
The GMI has been designed with a strict calibration accuracy requirement, enabling the instrument to serve as a microwave radiometric standard. The GMI features, ensuring its high calibration accuracy, include: protection of the hot load from Sun intrusion, noise diodes on the low-frequency channels for a dual calibration system, and a reflective antenna coating [33].

The GMI data used in this study are gridded products of total column water vapour (TCWV), in binary format provided by Remote Sensing Systems (RSS, http://www.remss.com/). Two $0.25^{\circ} \times 0.25^{\circ}$ global grids per day are provided, one containing the ascending and the other the descending GPM passes. The RSS products based on the Version-8.2 algorithm and the Radiative Transfer Model have been used [32].

As described in [34], the WTC has been computed from these TCWV products using the expression by [35], deduced from temperature and humidity profiles from ECMWF model fields:

$$
\mathrm{WTC}=-\left(\mathrm{a}_{0}+\mathrm{a}_{1} \mathrm{WV}+\mathrm{a}_{2} \mathrm{WV}^{2}+\mathrm{a}_{3} \mathrm{WV}^{3}\right) \mathrm{WV} \times 10^{-2}
$$

with $\mathrm{a}_{0}=6.8544, \mathrm{a}_{1}=-0.4377, \mathrm{a}_{2}=0.0714$, and $\mathrm{a}_{3}=-0.0038$. In Equation (3), $\mathrm{WV}$ is in centimetres, as provided in the TCWV products, and WTC results are in metres.

In [24] the WTC derived from a previous version of these products (Version 7, V7) was compared against the WTC derived from the SSM/IS on board the Defense Meteorological Satellite Program satellite series F16 and F17. The SSM/IS sensors can be regarded as a reference, due to their stability and independent calibration [36,37]. This comparison shows that the scale factor and offset between SSM/IS and GMI are 0.99 and $-0.26 \mathrm{~cm}$, respectively, while the Root Mean Square (RMS) of the differences between the two data sets is $0.79 \mathrm{~cm}$ and $0.77 \mathrm{~cm}$, before and after the adjustment to SSM/IS, respectively. According to RSS, the Version 8 (V8) brightness temperatures from GMI are slightly different from the V7 brightness temperatures; however there are no significant differences between the V7 and V8 ocean products. In the sequel, in this work the GMI V8.2 products have been adopted without applying any calibration parameters. It should be noted that, in spite of the fact that SSM/IS are considered stable sensors, the S3A WTC was not directly compared against the corresponding WTC derived from the SSM/IS TCWV products, also available from RSS, since both S3A, F16, and F17 are in Sun-synchronous orbits with a phase difference of 5-6 h (S3A/F16) and 3-5 h (S3A/F17).

\subsection{Microwave Radiometers on Board Jason-2, Jason-3, and SARAL}

Launched on 8 June 2008, the Ocean Surface Topography Mission (OSTM) Jason-2 carries the Advanced Microwave Radiometer (AMR) operating at 18.7, 23.8 and $34 \mathrm{GHz}$. In comparison with the dual-frequency MWR aboard the ESA missions, the additional low frequency channel improves the WTC retrieval, particularly by adding the ability to reduce land effects near the coast [38].

During the first years of the mission, like its predecessors TOPEX/Poseidon and Jason-1, Jason-2 flew in the so-called reference orbit: non-Sun-synchronous, inclination of $66^{\circ}$, altitude of $1336 \mathrm{~km}$, 10-day repeat cycle (127 orbits per cycle), and $315 \mathrm{~km}$ inter-track spacing at the equator [39]. Jason-3 was launched to the reference orbit on 17 January 2016. During the calibration phase of approximately 6 months (20 repeat cycles) it shared the same orbit with Jason-2, with a time difference of about $1 \mathrm{~min}$. In October 2016, Jason-2 moved to the interleaved orbit (same characteristics but with the ground tracks at half distance between those of the reference orbit) and later on, on 20 June 2017, to a long-repeat orbit, at an altitude of roughly $1309.5 \mathrm{~km}$.

Jason-3 carries the Advanced Microwave Radiometer 2 (AMR-2), which is similar to the AMR but with improvements in instrument thermal control and stability [40]. Jason-3 is the first altimeter mission to implement special spacecraft cold sky calibration manoeuvres (CSCMs), combined with vicarious on-Earth ocean and land target references, for improving the long-term climate calibration of the radiometer [41]. Currently, Jason-2 also performs routine CSCMs.

Launched on 25 February 2013, SARAL/AltiKa flies on the same orbit as ERS-2 and Envisat: Sun-synchronous with an LTDN at 18:00 h and a Local Time of Ascending Node (LTAN) at 06:00 h. 
It has an inclination of $98.5^{\circ}$, altitude of about $800 \mathrm{~km}$, a 35-day repeat cycle (501 orbits per cycle), and $80 \mathrm{~km}$ inter-track spacing at the equator [42]. SARAL caries the AltiKa instrument, provided by CNES, consisting of a Ka-band altimeter and an embedded dual-frequency Microwave Radiometer $(23.8 \mathrm{GHz} / 37 \mathrm{GHz})$ similar to that of Envisat but with a smaller footprint $(8 \mathrm{~km}$ in Ka-band and $12 \mathrm{~km}$ in Ku-band) [19].

\subsection{WTC from GNSS at Coastal Stations}

Zenith total delays (ZTDs) from a network of 60 stations with a good global coverage have been used. The details of this computation are given in [43], with only the main features being outlined here. These stations have been chosen to cover the various regions of the world with different WTC variability conditions (Figure 1) and to ensure that all zenith wet delays (ZWDs) have been obtained using the same computation parameters, thus ensuring their long-term stability. All stations are located near the coast, up to $100 \mathrm{~km}$ from the coast and with an orthometric height $<1000 \mathrm{~m}$. The second condition aims at reducing the errors due to the height dependence of the WTC.

As illustrated in the background map of Figure 1, derived from ECMWF operational model fields, the RMS of the WPD has a clear zonal dependence, ranging from only a few $\mathrm{cm}$ near the poles up to $35 \mathrm{~cm}$ at low latitudes. The patterns of the RMS of WPD are dominated by the zonal dependence, associated with the dependence of the WPD on temperature and the increase in water vapour in the equatorial regions. The variance of the WPD (not shown) also has a strong dependency on latitude, reaching a maximum near the tropics, over regions where the conditions for strong monsoons prevail, and a minimum near the poles, where the content of water vapour in the atmosphere is minimal. Maximum values occur in the Northern Hemisphere, where the Indian and Pacific oceans meet; in the Southern Hemisphere, the highest variability is found northwards of Australia.

The GNSS provides accurate $(4-6 \mathrm{~mm}$ ) values of the ZTD, the sum of the dry and wet components of the tropospheric delay, at station height, while the quantity of interest in this study is the zenith wet delay (ZWD), symmetric with respect to the WTC, at sea (zero height) level. The latter is obtained from the ZTD at station level by subtracting the dry correction or zenith hydrostatic delay (ZHD) derived from the ECMWF sea-level pressure (SLP) field using the modified Saastamoinen model [44] and reducing ZHD and ZWD fields to sea level using the expression by [45], with modifications introduced by [46].

It has been shown [46] that the hydrostatic component of the tropospheric delay can be estimated from global grids of sea level pressure available from ECMWF models with an accuracy of 1 to $3 \mathrm{~mm}$ at a global scale, provided an adequate model for the height dependence of atmospheric pressure is adopted. Therefore, using ZHD computed from ECMWF model fields according to [46], the ZWD can be determined from the GNSS with an accuracy greater than $1 \mathrm{~cm}$.

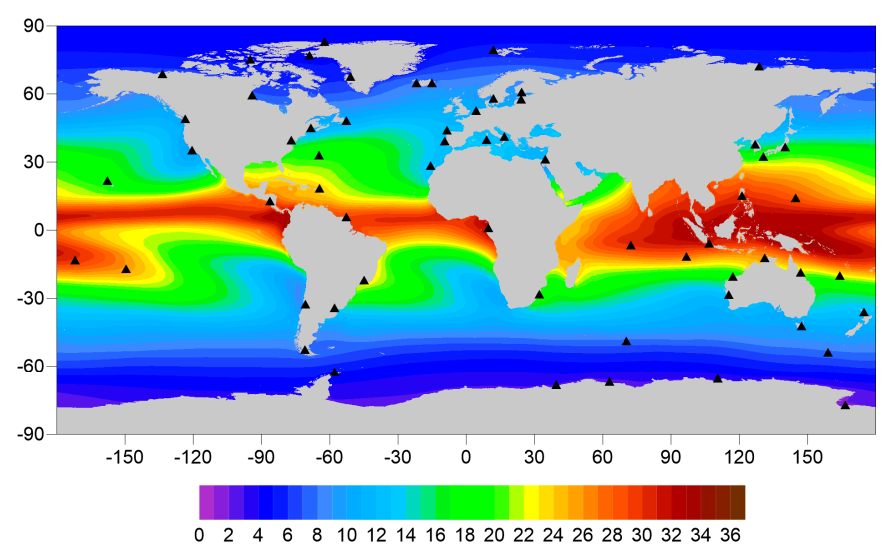

Figure 1. Location of a set of 60 Global Navigation Satellite System (GNSS) stations used in this study (adapted from [43]). The background map represents the Root Mean Square (RMS) of wet path delay (WPD) in $\mathrm{cm}$. 


\subsection{GPD+ Wet Tropospheric Corrections}

GNSS-derived Path Delay Plus (GPD+) provides wet tropospheric corrections derived by data combination, using space-time objective analysis, of all available wet path delays in the neighbourhood of a given point on the Earth. It has been designed: (1) to correct the WTC observations derived from the on-board MWR flagged as invalid due to various error sources: contamination by land, ice or rain, or instrument malfunction; and (2) to estimate improved WTC for satellites such as CryoSat-2, with no on-board MWR, for which only the model-derived WTC was available. In the first case, for all points with good MWR data, GPD+ keeps these values unchanged while for all invalid MWR measurements, a new estimate is obtained from the available observations. In the second case, a new estimate is obtained for all along-track points. Whenever the number of observations is null, GPD+ assumes the value of the first guess, which is the WTC from an atmospheric model: ECMWF operational for the most recent missions [47] and EMWF ReAnalysis (ERA) Interim for all missions with data prior to $2004[23,24,48]$.

An important step in the GPD+ retrievals is the efficiency of the criteria to depict all invalid observations. This is done by using various flags provided with satellite data, when available, for example regarding the presence of land, ice, or rain in the radiometer footprint, or the distance from coast. Moreover, statistical criteria are established based on the comparison of MWR values and the corresponding model values, not only on the same point but also in the neighbouring along-track points. Figure 2 illustrates the invalid MWR points for Sentinel-3A cycle 06 (28.6\% of the total ocean points). When only points with valid SLA are considered, the percentage of invalid MWR points varies, from cycle to cycle, from $11 \%$ to $17 \%$.

For this study, two types of GPD+ WTC have been computed for S3A: (1) using only third-party data, i.e., wet path delays derived from a set of more than 800 GNSS stations and WTC from scanning imaging MWRs on board various remote sensing missions, hereafter designated GPD1; and (2) using all data including the S3A MWR measurements, provided they are valid, and only computing new estimates for the invalid MWR points, hereafter named GPD2.

The available WTC observations used in the GPD+ estimations, spanning the S3A mission period, include: valid observations from S3A's on-board MWR; scanning imaging MWRs (SI-MWRs) from 11 different satellites; and GNSS-derived WTCs from more than 800 coastal stations.

Details on these data sets and on the GPD+ algorithm can be found in [24].

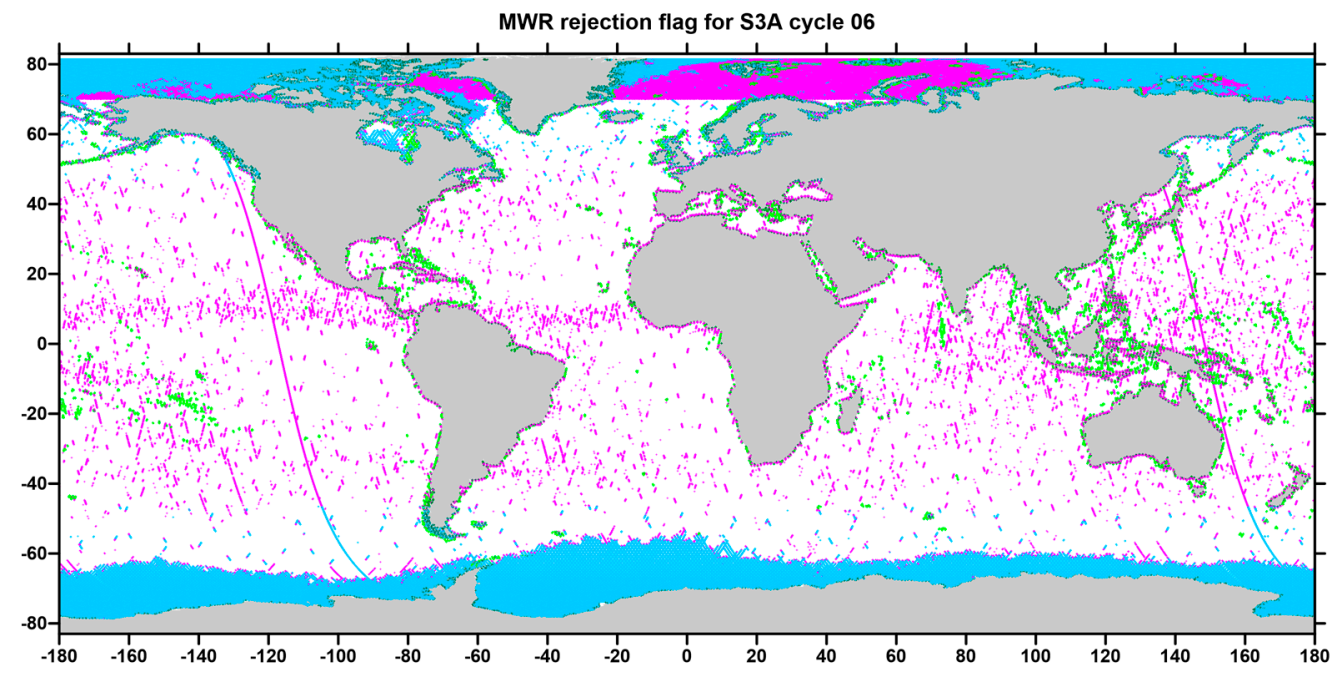

Figure 2. Sentinel-3A (S3A) points for cycle 06 with invalid microwave radiometer (MWR) observations: green-land contamination; blue-ice contamination; pink—rain, outliers, or additional condition such as all points above latitude $70^{\circ} \mathrm{N}$ or below $70^{\circ} \mathrm{S}$. 


\subsection{The ECMWF Atmospheric Model}

The atmospheric model used in this study is the ECMWF operational model. Global $0.125^{\circ} \times 0.125$ grids of three single-level atmospheric parameters (sea level pressure (SLP), surface temperature (2-m temperature, 2T) and total column water vapour (TCWV)), available every $6 \mathrm{~h}$ have been used [49].

These model parameters are used both in the ZWD computations referred in Section 2.4 and to determine a model derived WTC for each S3A along-track position by space-time interpolation from the two closest grids, 6-h apart. In spite of its poor temporal sampling, the ECMWF model is used from here on as an additional point of comparison.

\section{Results}

Section 3 presents the various analyses performed aimed at a detailed assessment of the MWR-based wet tropospheric correction present on the Sentinel-3A products described in Section 2.1. In this section only the results are presented, their full discussion being described in Section 4.

\subsection{Comparison with Other Microwave Radiometers}

This section presents the comparison of Sentinel-3A MWR with other microwave radiometers on board the GMI, J2, J3 and SARAL. In these comparisons with other sensors, the wet path delay (WPD, symmetric with respect to the WTC) has been used. Unless otherwise mentioned, all statistical parameters detailed in this section (scale factor, offset, mean, and RMS of differences) refer to WPD. This is done to facilitate the representation and interpretation of the results.

\subsubsection{Comparison with GMI}

For the comparison with GMI, match points between GPM and S3A with a time difference $\Delta \mathrm{T}$ $<45 \mathrm{~min}$ and within a distance $\Delta \mathrm{D}<50 \mathrm{~km}$ were computed. Only S3A points considered valid by the GPD+ algorithm [24] have been used (see Section 2.5). These criteria aim at removing S3A MWR observations contaminated by e.g., land, ice, rain, and outliers (Figure 2).

The use of match or collocated points is common practice in the comparison of a pair of sensors, thus comparing the measurements from both sensors in points with a given space-time difference. When analysing long periods of data, other approaches are possible such as e.g., in [50] where the authors organised the data sets in monthly bin boxes of three degrees, claiming that this approach is more favourable in e.g., the analyses of temporal variations of geophysical variables such as the WPD. Considering the short time span of the S3A dataset under inspection, match points are considered in this study.

Figure 3 illustrates the match points between GPM and S3A for the 10-month period of this study. The colour scale represents WPD differences between GMI and S3A in cm. Red colours mean that GMI measurements indicate wetter conditions than S3A, while blue colours indicate the opposite. The overall mean and RMS of the differences WPD(GMI)-WPD(S3A) are $0.17 \mathrm{~cm}$ and $0.95 \mathrm{~cm}$, respectively (see Table 1).

Figure 4 illustrates the scattergram of the WPD from S3A against the WPD from the GMI (left) and against WPD difference between the GMI and S3A (right), using the whole set of match points ( 219,000 points). The scale factor is 1.004 and the offset is $0.12 \mathrm{~cm}$, indicating a very good overall agreement between the two radiometers, with the GMI measurements indicating slightly wetter conditions than S3A.

Figures 5 and 6 illustrate the time evolution of the WPD from both sensors and the respective differences. The top panel of Figure 5 represents the time evolution of the WPD from the GMI (blue) and S3A (pink) while the bottom panel shows the corresponding WPD differences between the GMI and S3A. A strong periodic signal of approximately 41 days (41.1 days) can be observed, due to GPM orbit plane rotation with respect to the Sun. It can be seen that this periodic pattern is due to the 
changes in the spatial sampling of the match points with time (cf. Figures 5 and 7 and discussion in Section 5).

When daily and 27-day RMS differences are computed (Figure 6), the same periodic pattern is shown, now at 82 days, and seem stable.

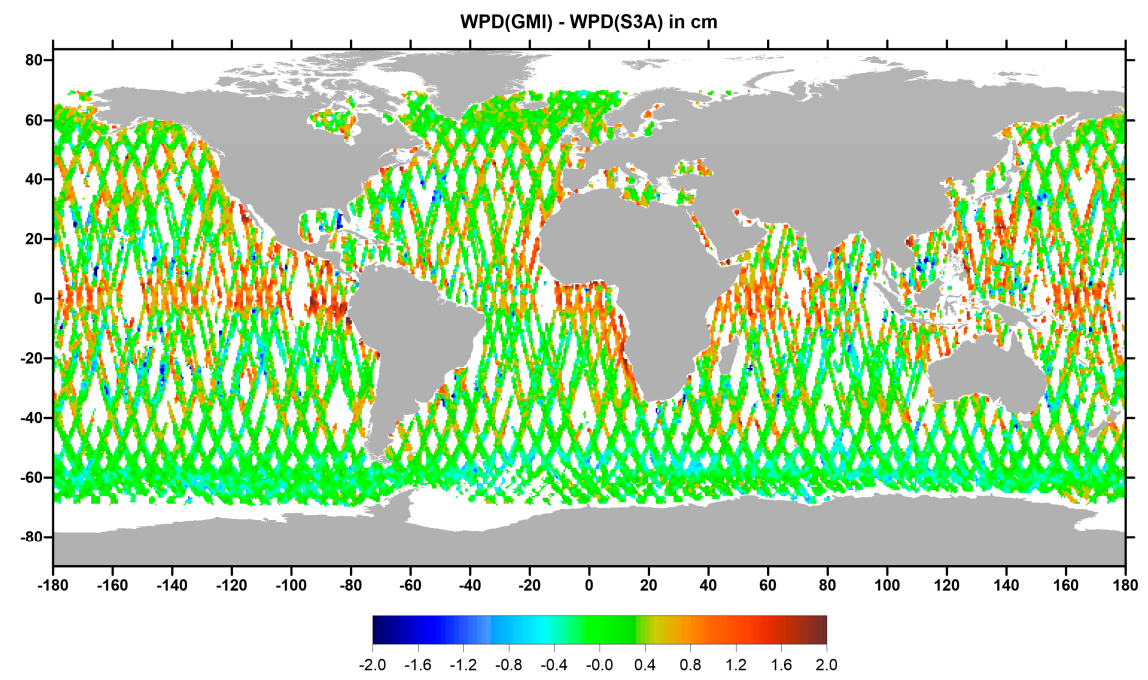

Figure 3. Spatial coverage of match points between S3A and the Global Precipitation Measurement (GPM) Microwave Imager (GMI) with time difference $\Delta \mathrm{T}<45 \mathrm{~min}$ and distance $\Delta \mathrm{D}<50 \mathrm{~km}$, for S3A cycles $05-16$, used in this study ( 219,000 points). Colour scale indicates WPD differences between the GMI and S3A in $\mathrm{cm}$.

Table 1. Statistical parameters of the comparison between the WPD from Sentinel-3A and other WPD sources. ECMWF: European Centre for Medium-Range Weather Forecasts; GPD: GNSS-derived Path Delay Plus; WTC: wet tropospheric correction; J2: Jason-2; J3: Jason-3; SARAL: Satellite with ARgos and ALtika.

\begin{tabular}{ccccc}
\hline WTC/S3A & Scale Factor & Offset $(\mathbf{c m})$ & Mean Diff. (cm) & RMS Diff. (cm) \\
\hline GMI/S3A & 1.004 & 0.115 & 0.171 & 0.947 \\
J2/S3A & 1.010 & -0.660 & -0.556 & 1.213 \\
J3/S3A & 1.012 & -0.831 & -0.698 & 1.292 \\
SARAL/S3A & 0.955 & 0.557 & 0.029 & 1.536 \\
ECMWF/S3A & 1.013 & -0.086 & 0.098 & 1.256 \\
GPD1/S3A & 1.005 & 0.173 & 0.251 & 0.967 \\
\hline
\end{tabular}

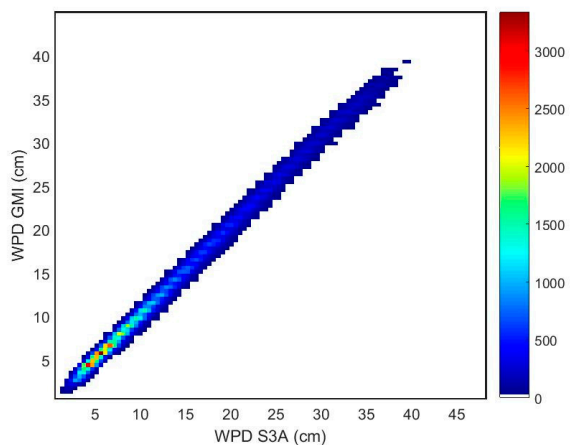

(a)

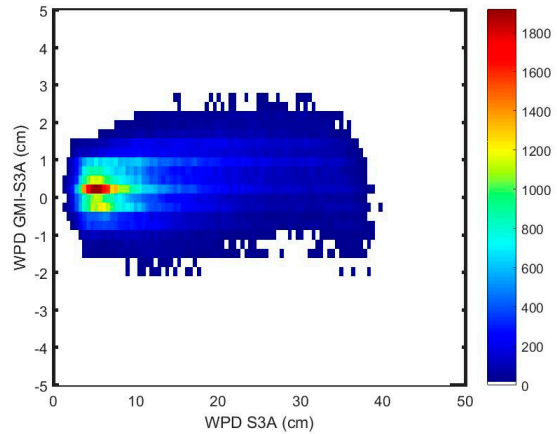

(b)

Figure 4. (a) Wet path delay from S3A versus WPD from the GMI; (b) WPD from S3A versus WPD differences between the GMI and S3A ( 219,000 points). 

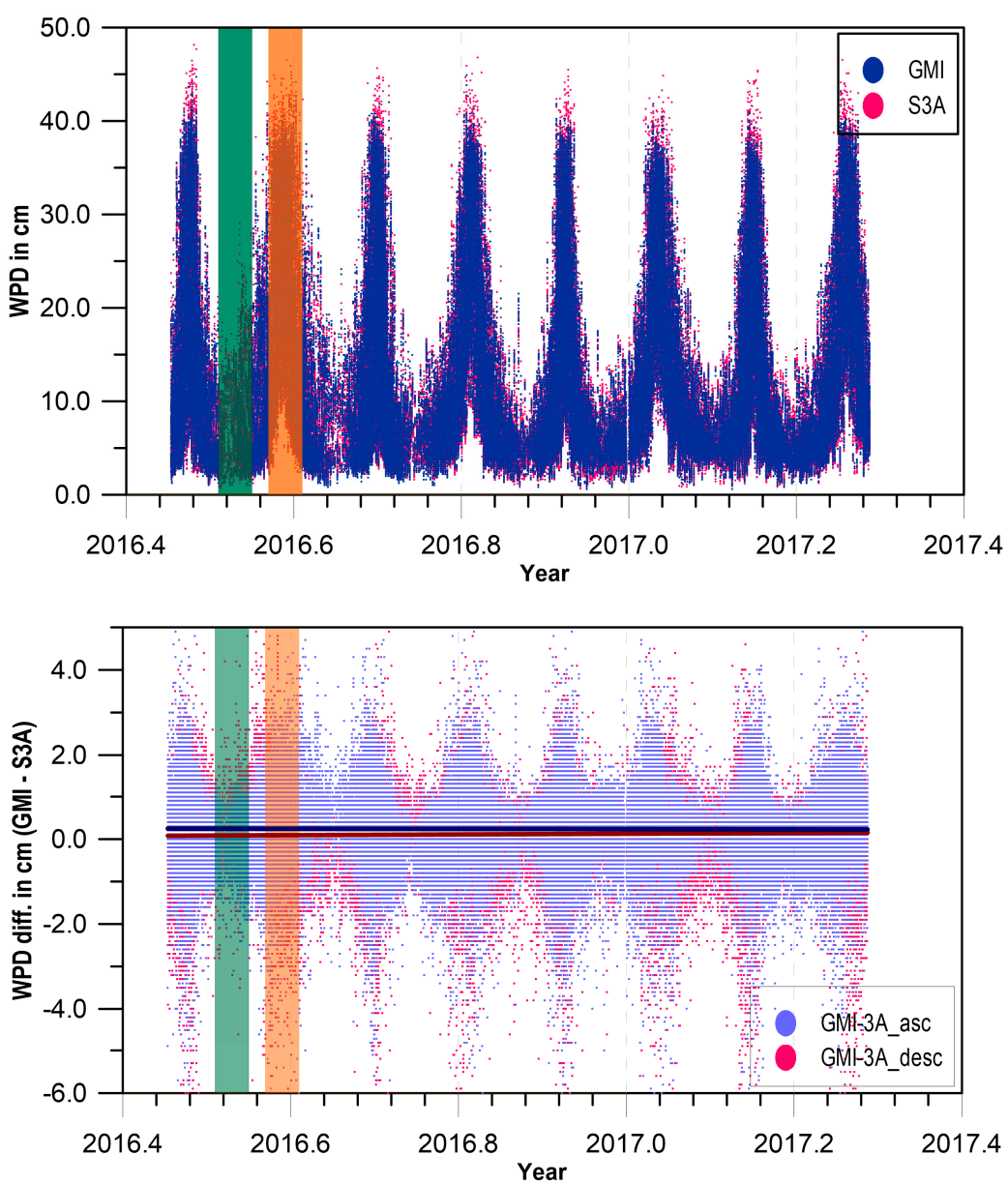

Figure 5. (Top panel): time evolution of the WPD from the GMI (blue) and S3A (pink); (Bottom Panel): time evolution of WPD differences between the GMI and S3A for ascending passes (blue) and descending passes (red). Colour bars refer to periods when the GMI/S3A match points are all located at high latitudes (green points in Figure 7) or low latitudes (orange points in Figure 7) to which correspond smaller or larger WPD variability.

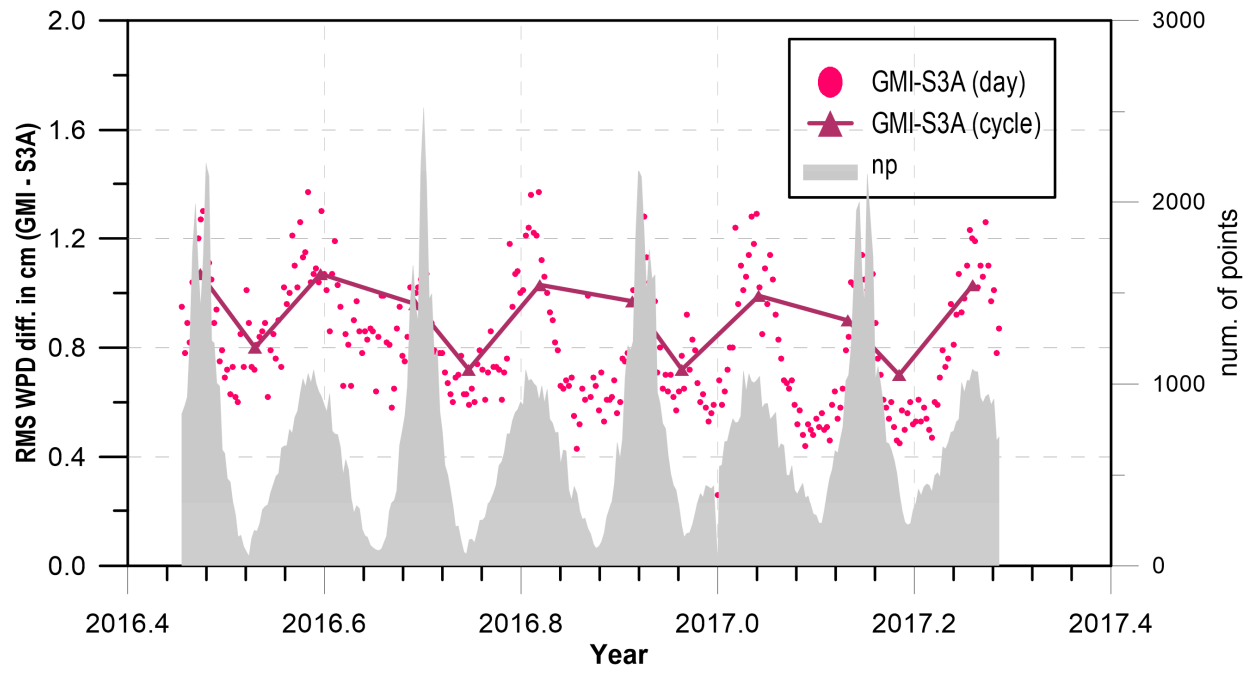

Figure 6. Time evolution of the daily RMS of the WPD differences between the GMI and S3A. The number of points is represented by " $n \mathrm{p}$ ". 


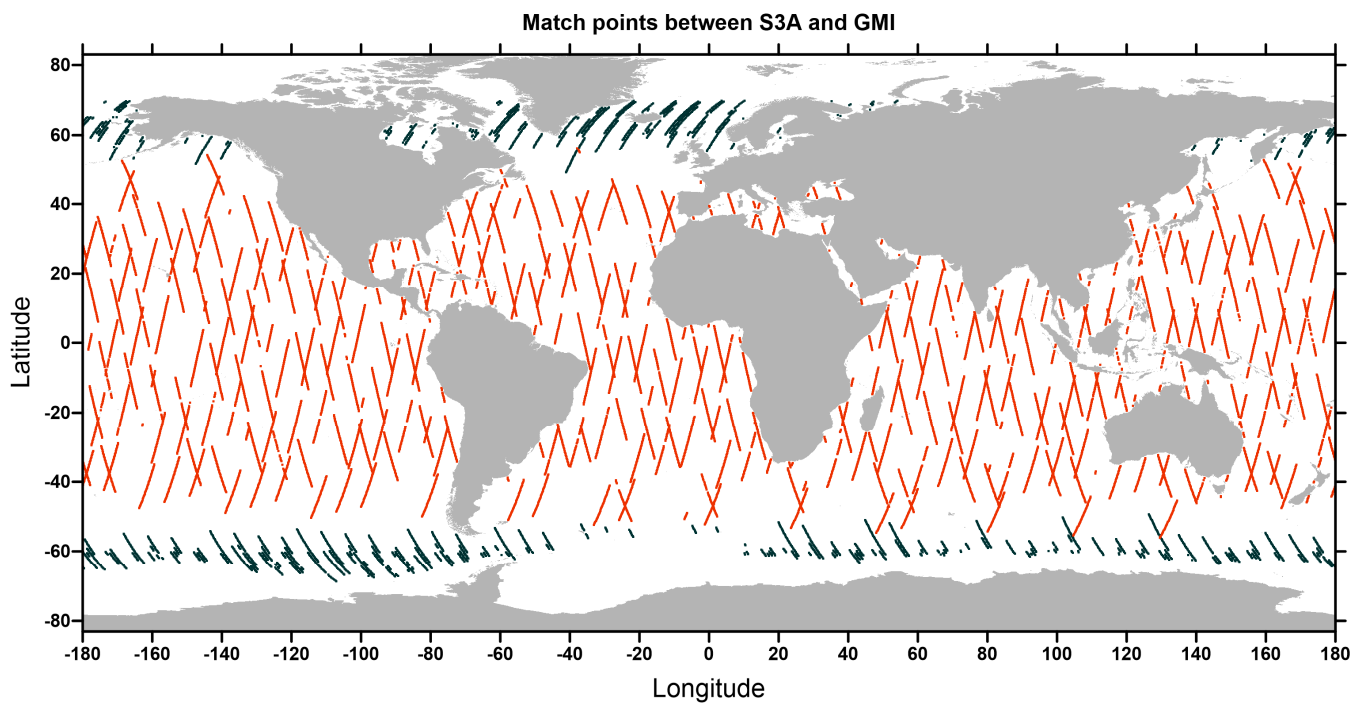

Figure 7. Match points between the GMI and S3A. Colours correspond to different time periods, indicated in Figure 5 by the corresponding colour bars.

\subsubsection{Comparison with the MWR on Board Jason-2, Jason-3, and SARAL}

To compare the WPD from S3A with that from Jason-2 (J2), Jason-3 (J3), and SARAL, the differences between the corresponding WPD at the crossovers between these missions have been computed. For this purpose, crossovers between S3A and Jason-2 and between S3A and Jason-3 with time difference $\Delta \mathrm{T}<180 \mathrm{~min}$ have been computed. Note that both S3A and SARAL have Sun-synchronous orbits, with S3A LTAN at 22:00 $\mathrm{h}$ (LTDN at 10:00 h), and SARAL LTAN at 06:00 $\mathrm{h}$ (LTDN at 18:00). Thus, $240 \mathrm{~min}(4 \mathrm{~h})$ is the minimum time interval to get crossovers between the two missions at low latitudes. With a 4-h difference, every ascending/descending S3A pass crosses a descending/ascending SARAL track. If a smaller period is considered, crossovers are all located at high latitudes, the corresponding values not being representative of the whole set of WTC variability conditions. For example, within a time interval of $180 \mathrm{~min}$, all crossovers are above latitude $40^{\circ}$ and below latitude $-40^{\circ}$. In the sequel, for SARAL crossovers with time difference $\Delta \mathrm{T}<240 \mathrm{~min}$ have been considered.

Figure 8 illustrates the spatial pattern of the WPD differences between J2, J3, SARAL, and S3A. The mean and RMS differences between J2, J3, SARAL, and S3A are presented in Table 1. Mean values are $-0.56 \mathrm{~cm},-0.70 \mathrm{~cm}$ and $0.03 \mathrm{~cm}$, respectively, while the corresponding RMS are $1.21 \mathrm{~cm}, 1.29 \mathrm{~cm}$, and $1.54 \mathrm{~cm}$. The overall agreement with $\mathrm{J} 2$ and J3 is better than with SARAL, somehow expected since the crossovers with SARAL have a larger time difference.

Figure 9 shows the scattergrams of the WPD from S3A against the WPD from the various sensors (left panels) as well as against the difference between the WPD from each sensor and that from S3A (right panels). The scale factors and offsets for J2 and J3 are very similar: same scale factor (1.01) and offsets of $-0.66 \mathrm{~cm}$ and $-0.83 \mathrm{~cm}$, respectively. The scale factor for SARAL is slightly different (0.96) with an offset of $0.56 \mathrm{~cm}$. These scatterplots indicate that the best agreement is with J3 and the worst is with SARAL, due to the large time difference between the S3A/SARAL crossover points. Both Figures 8 and 9 indicate that J2 and J3 measure drier than S3A by about $0.6-0.8 \mathrm{~cm}$, while SARAL measurements indicate wetter conditions than S3A by about $0.6 \mathrm{~cm}$.

Figure 10 depicts the time evolution of the WPD differences between J2, J3, SARAL and S3A (daily and 27-day RMS values in centimetres). These results indicate that in spite of the small span of the data, there is an overall agreement between all analysed sensors. 

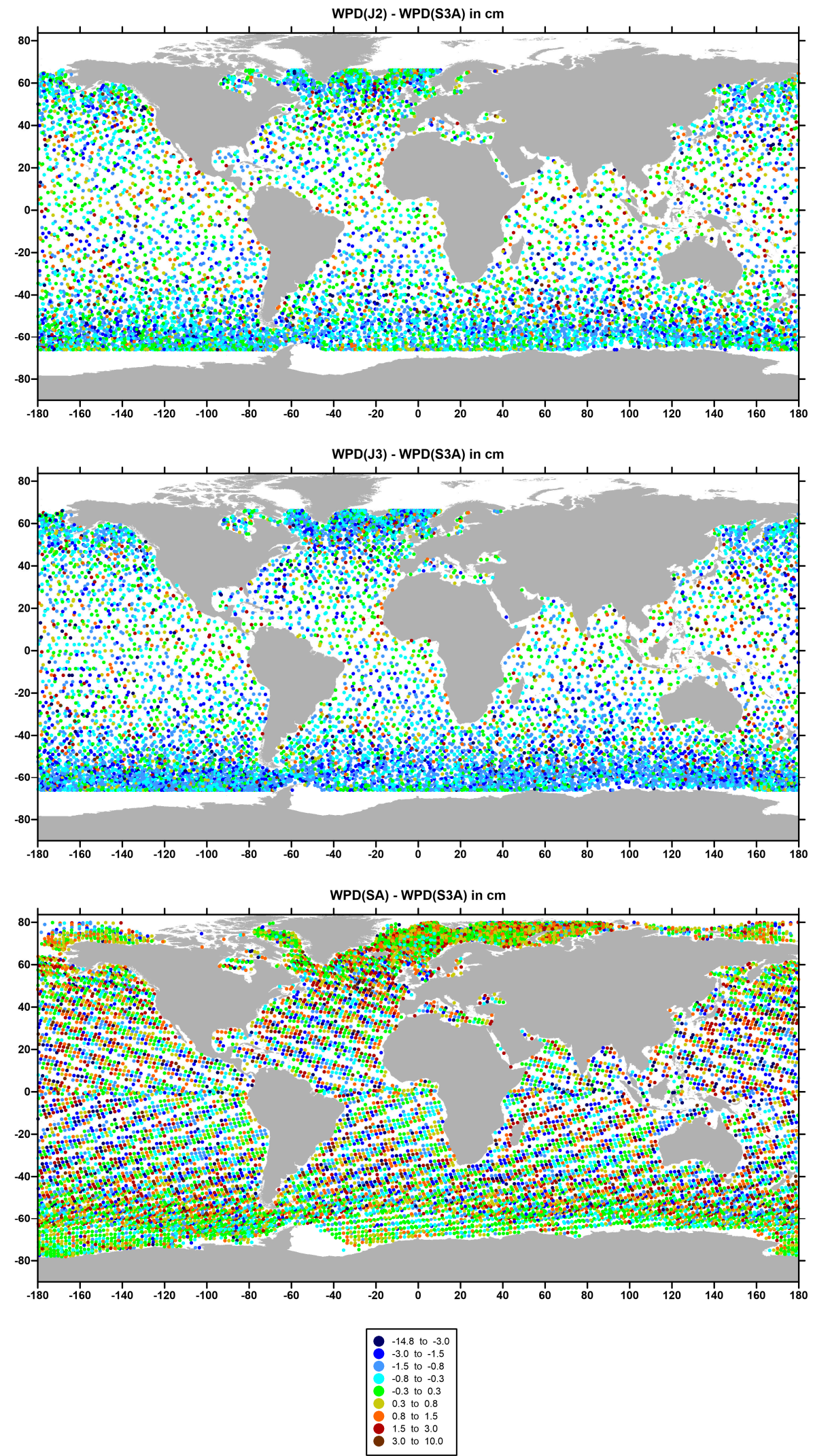

Figure 8. (Top panel): Crossover points between $\mathrm{J} 2$ and S3A with $\Delta \mathrm{T}<180 \min (\sim 11,600$ points); (Middle panel): crossovers between J3 and the S3A with $\Delta \mathrm{T}<180 \mathrm{~min}(\sim 12,600$ points); (Bottom panel): crossovers between SARAL and S3A with $\Delta \mathrm{T}<240 \min (\sim 13,700$ points). 

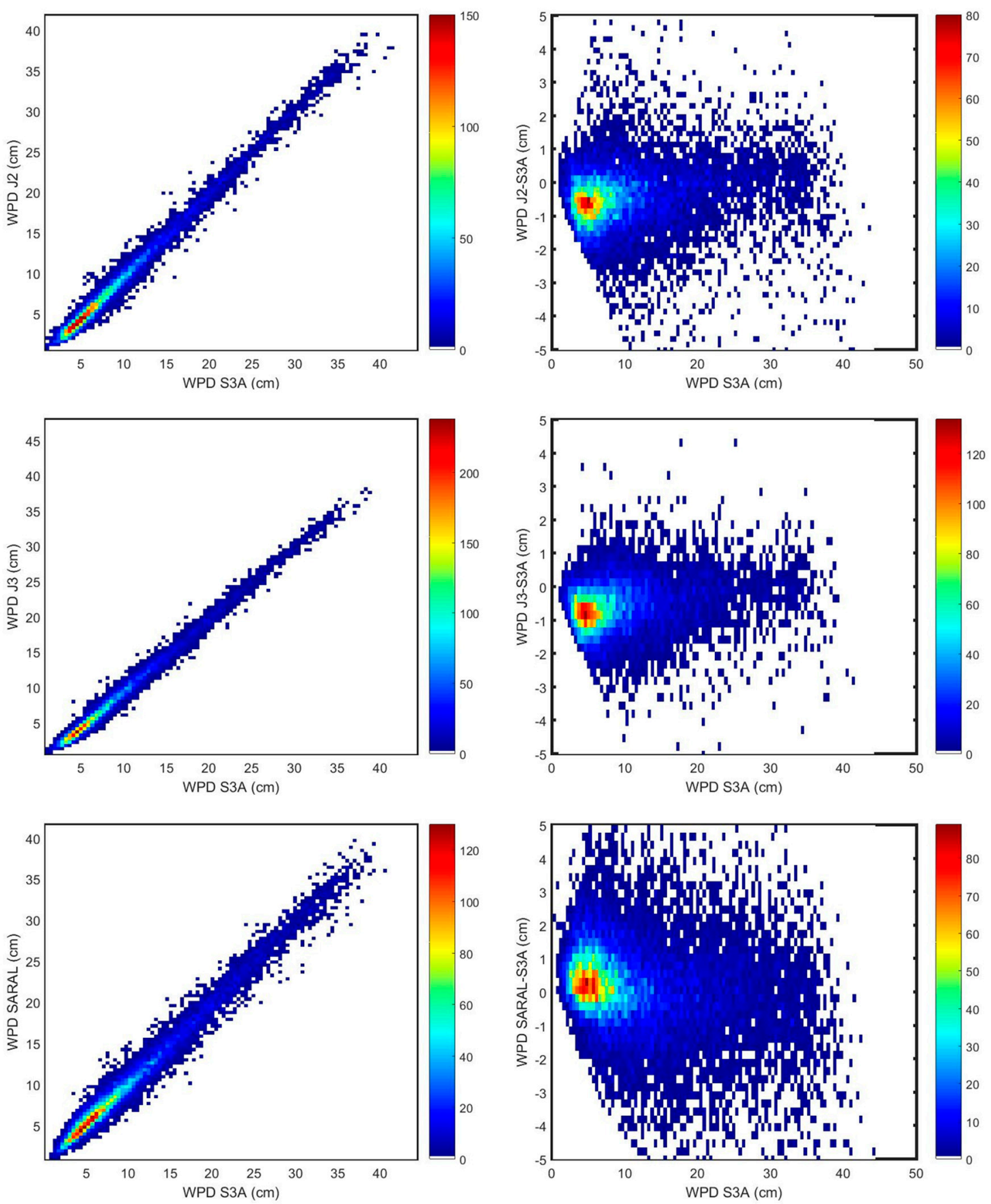

Figure 9. (Left panels): WPD from S3A versus WPD from J2 (top), J3 (middle), and SARAL (bottom), in cm; (Right panels): WPD from S3A versus WPD difference between J2 and S3A (top), between J3 and S3A (middle) and between SARAL and S3A (bottom). 

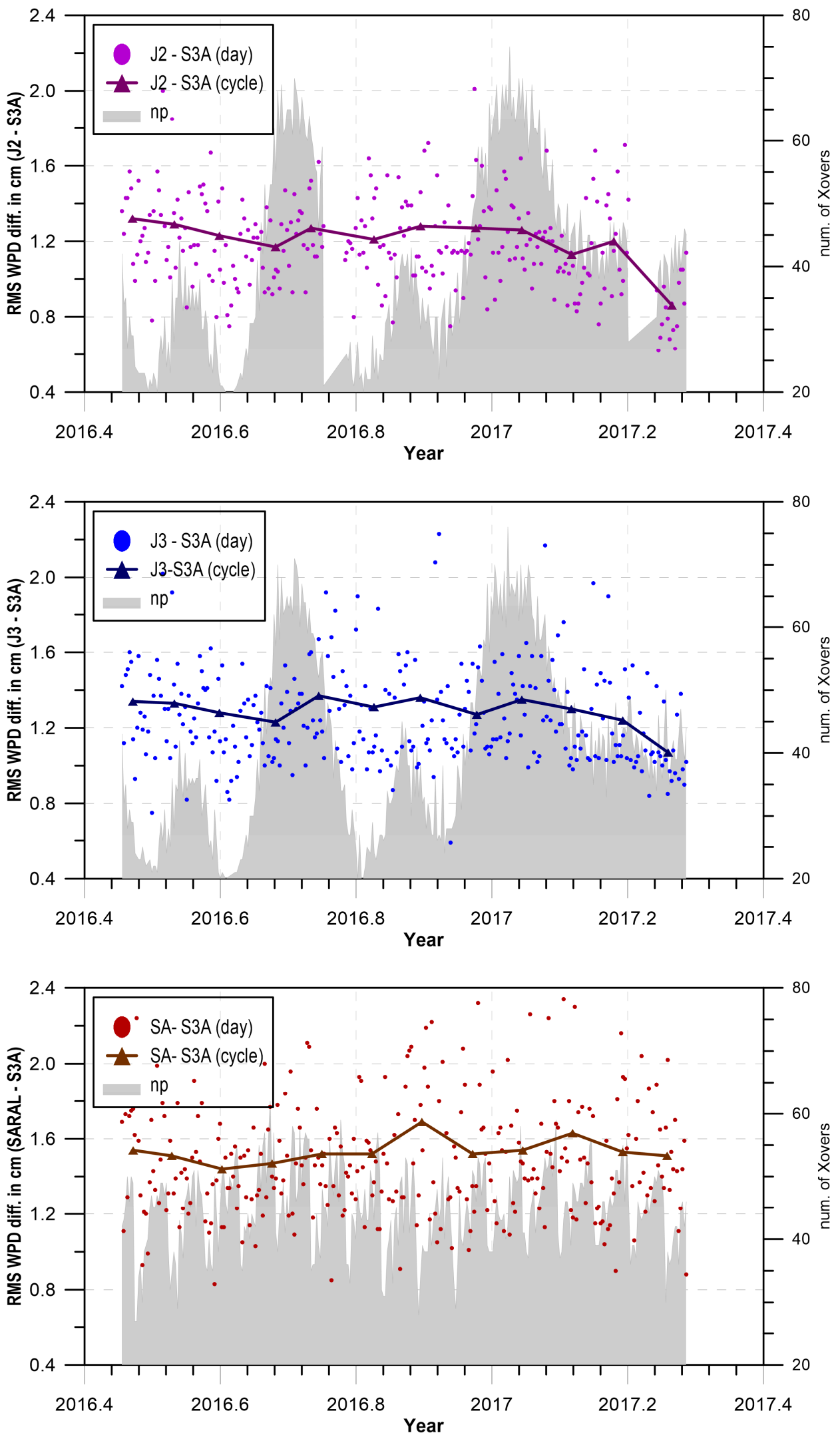

Figure 10. Time evolution of daily and 27-day RMS WPD differences between J2 and S3A (Top), between J3 and S3A (Middle), and between SARAL and S3A (Bottom), in cm. 


\subsection{Comparison with GNSS}

Figure 11 shows the non-collocated comparison with the WTC derived at 60 GNSS stations, as described in Section 2.4. In the comparisons with S3A MWR, only valid MWR observations, except those related with the criterion for land contamination, have been selected. This means that the observations flagged as invalid due to all other error sources (ice and rain contamination and outliers) have been removed. In the comparisons with GPD+ all points have been used. For each epoch of the S3A measurement, a WTC from each GNSS station is linearly interpolated in time. Then, the WTC differences from all stations are binned in classes of distance from coast and the corresponding RMSs are computed.

As the GNSS stations are over land and the MWR measurement points are over the ocean, the distance from coast is also directly related with the distance between the points under comparison. Therefore, the RMS differences between the WTC from either the S3A MWR or GPD+ generally increase with the distance from coast, reaching a minimum at the maximum distance at which land contamination occurs in the MWR observations. Differences between the WTC computed at GNSS stations and derived from S3A MWR (or GPD+) are expected to increase as the distance to the GNSS station increases, as both measurements start to become decorrelated.

The RMSs of the differences between the WTC from GNSS and the WTC from S3A MWR (or the corresponding WPD) show that contamination is observed up to $20-25 \mathrm{~km}$, in line with instrument specifications, the RMS of differences at these distances being about $1.8 \mathrm{~cm}$. On the other hand, no land contamination is observed in the RMS of differences with respect to GPD+ (GPD1 mentioned above), being always smaller than those with respect to the MWR by about $0.3 \mathrm{~cm}$, reaching $1.2 \mathrm{~cm}$ near the coast.

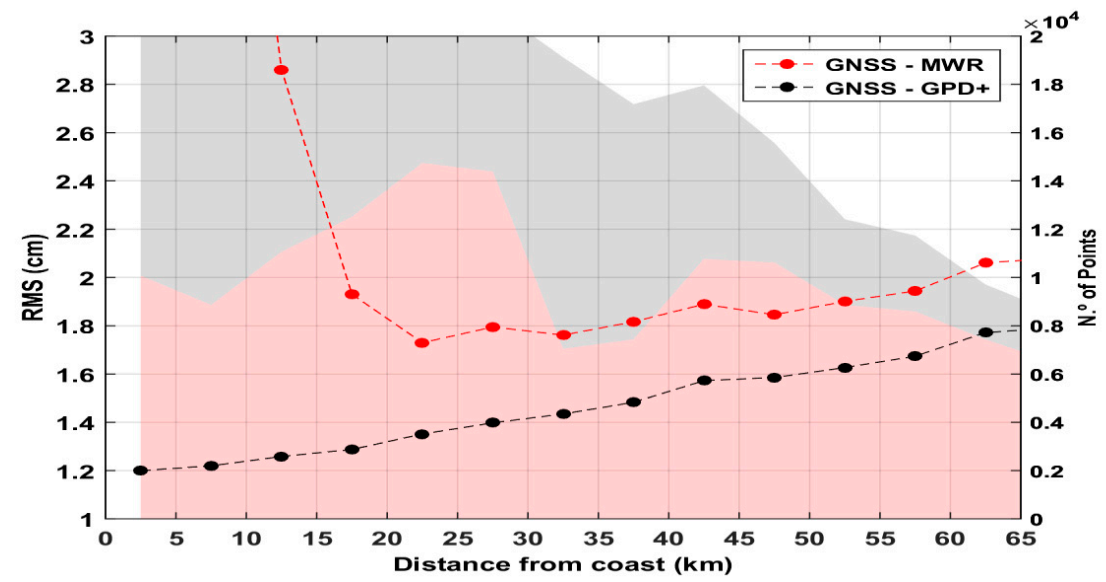

Figure 11. RMS differences between the WTC from the GNSS at coastal stations and the WTC from the S3A MWR, in $\mathrm{cm}$. The grey and red coloured bars represent the number of points in each class of distance for GPD1 and the MWR, respectively.

\subsection{Comparison with an Independent GPD+WTC, ECMWF Operational Model and the Composite WTC}

As mentioned in Section 2.5, two types of GPD+ WTC have been computed for S3A cycles 06 to 16: (1) GPD1-using only third-party data; and (2) GPD2-using all data including the S3A MWR. GPD1 WTC can be used as an external dataset, allowing an independent assessment of the S3A WTC. In the second case, GPD2 preserves the S3A MWR-derived WTC, whenever flagged as valid. Only new estimates are computed for the invalid points, using all available observations. The comparison between these two WTCs and between them and the S3A MWR-derived WTC (the latter comparison being performed only at valid MWR observations) gives further insight into the quality of the MWR observations, since it is performed using all S3A points and not only a subset (match points), as is the case of the comparison with the other MWR sensors. 
Figure 12 shows an example where the different WTCs from S3A MWR, ECMWF operational model, GPD1 (top) and GPD2 (bottom) are compared for S3A pass 340, cycle 06. Figure 13 shows the corresponding plots for pass 462 , same cycle. In these plots, only points with valid SLA are shown. Ice, land, and rain contamination can be observed in the MWR-derived WTC, more pronounced in pass 462 than in pass 340. Figure 14 illustrates the spatial distribution of the RMS of the WPD differences (cm) between GPD1 and S3A MWR for the whole period of study (cycles 05 to 16).

Figure 15 shows the time evolution of the RMS of the differences between the S3A MWR WTC and those from GPD1 and ECMWF, only for the valid MWR points. Note that for these points, GPD2 is equal to the MWR, so these differences are not shown.
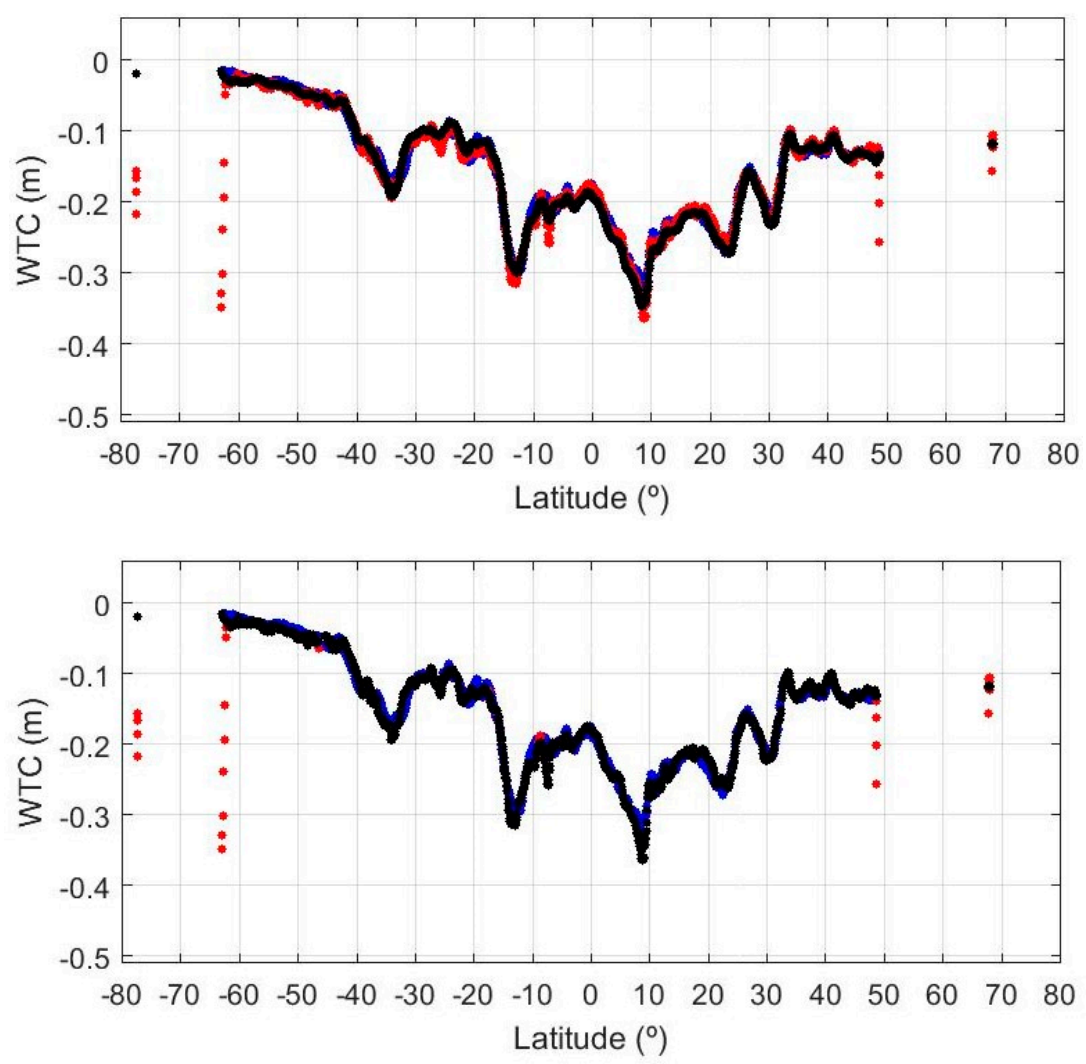

Figure 12. WTC (in metres) for S3A pass 340, cycle 06: ECMWF Operational (blue), MWR (red) and GPD (black, GPD1 in the top plot, GPD2 in the bottom plot) functions of latitude. The plot order is as mentioned in this caption. Thus, whenever the blue points cannot be seen, they are overlaid by the red and/or black points.

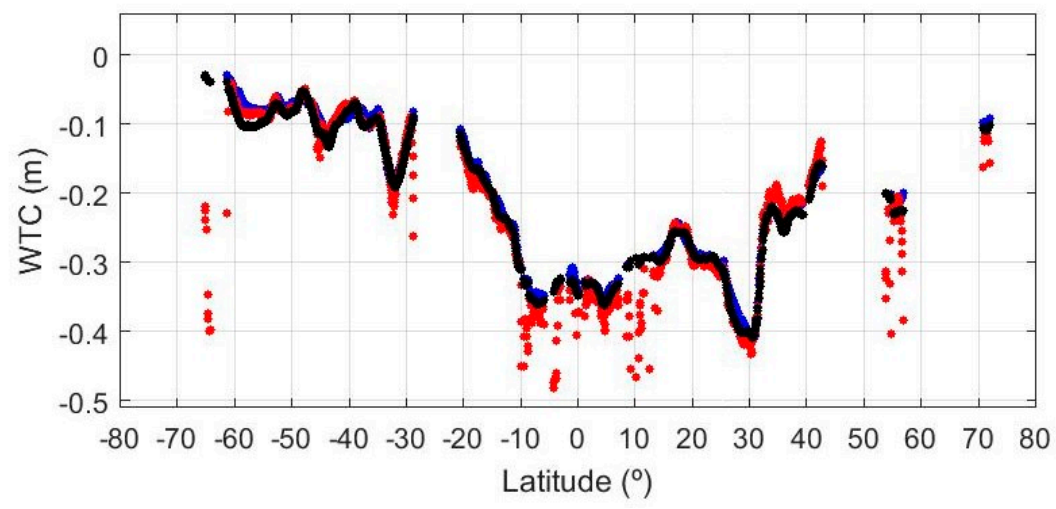

Figure 13. Cont. 


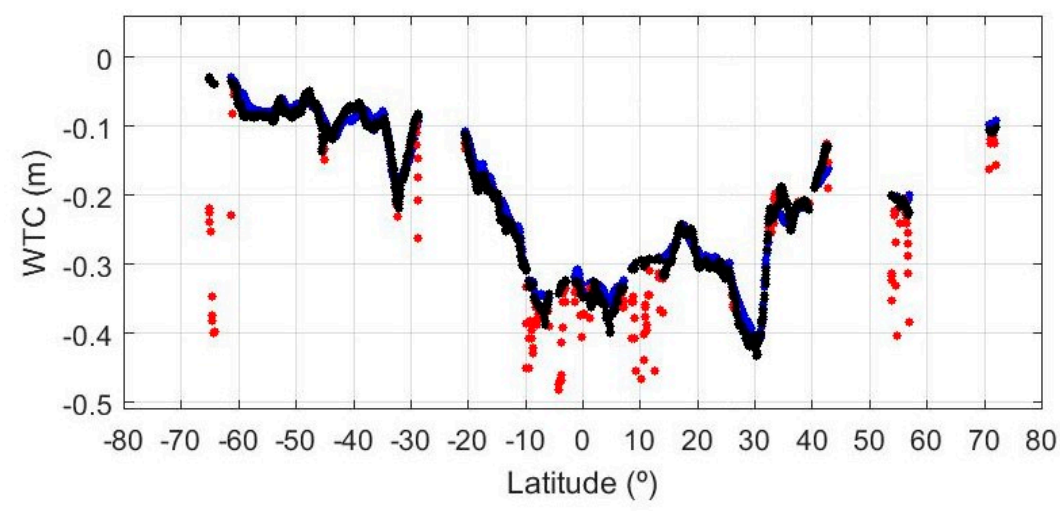

Figure 13. Same as in Figure 12 for S3A pass 462, cycle 06.

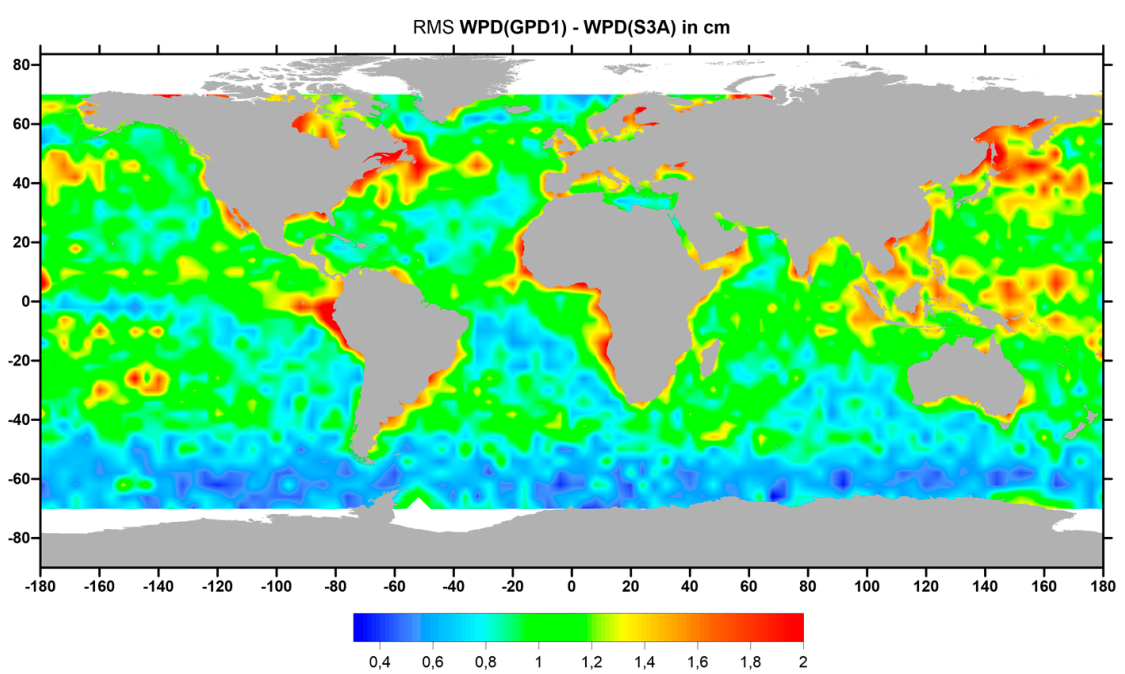

Figure 14. Spatial distribution of the RMS values of the WPD differences $(\mathrm{cm})$ between GPD1 and the S3A MWR, for cycles 05 to 16.

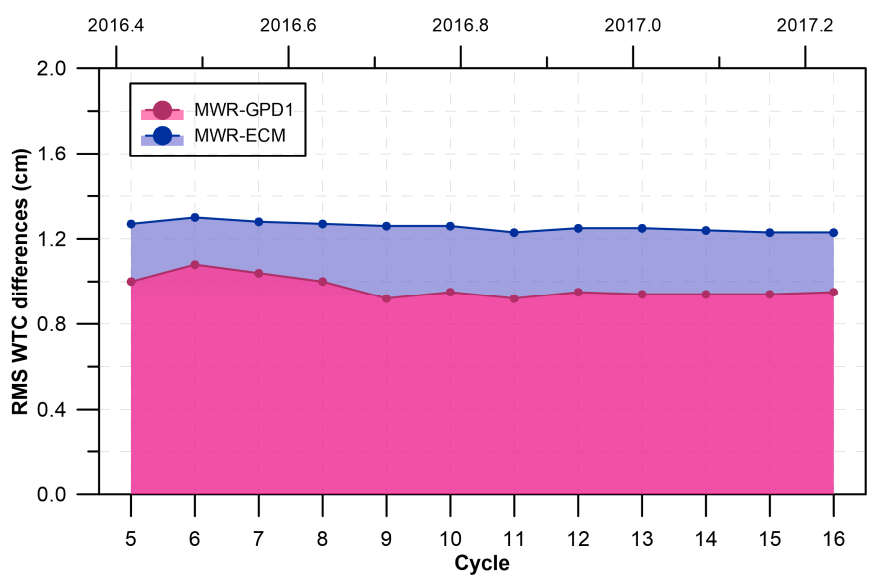

Figure 15. Time evolution of the RMS differences between the S3A MWR-based WTC and those from GPD1 and ECMWF.

The left panel of Figure 16 presents the scatterplots of the WPD from S3A versus the WPD from ECMWF (top) and GPD1 (bottom) in $\mathrm{cm}$, while the right panel shows the corresponding scatterplots against the WPD differences between ECMWF and S3A (top) and between GPD1 and S3A (bottom), 
evidencing the good agreement between all WPD, better with respect to GPD1 than to the model, in line with the statistical parameters shown in Table 1.
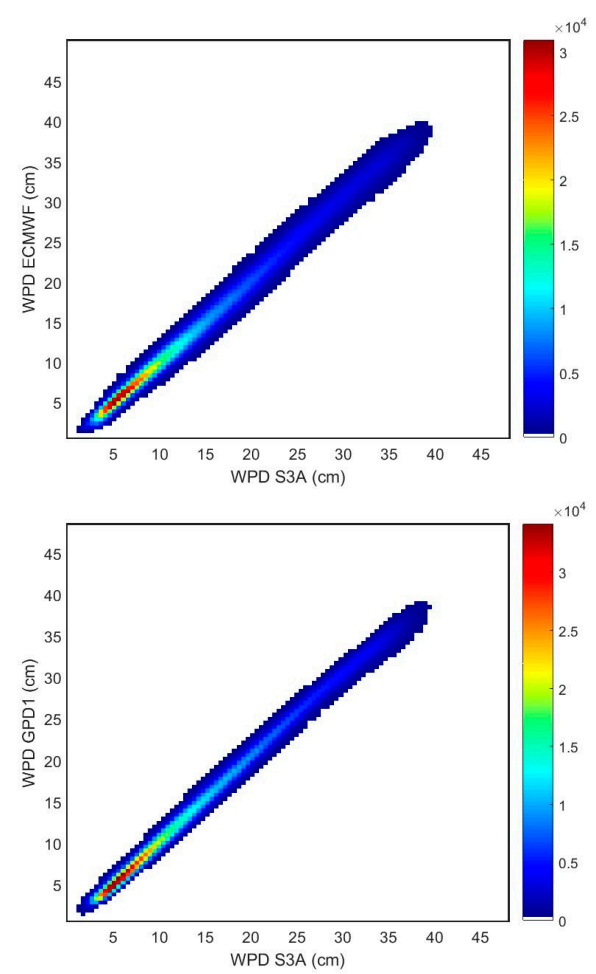
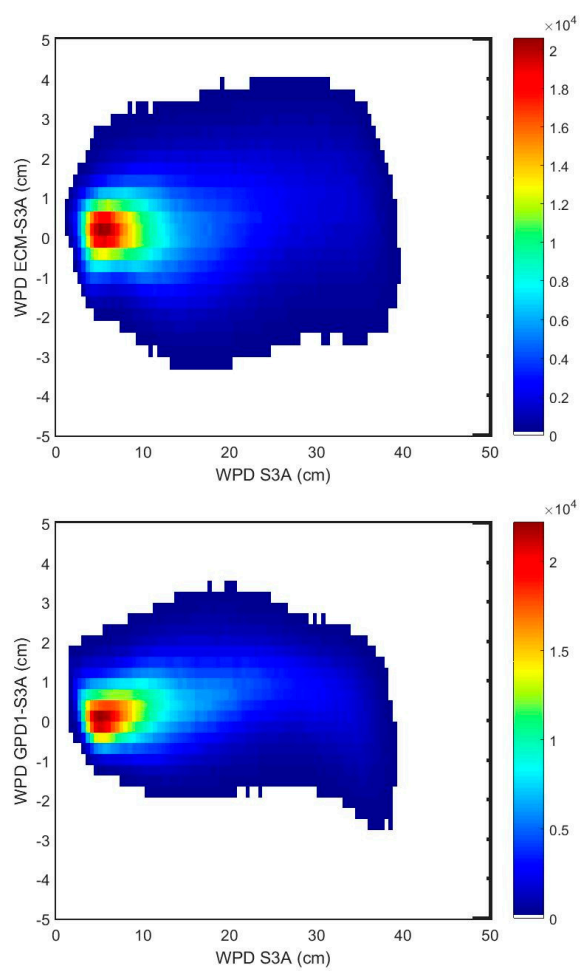

Figure 16. (Left panels): WPD from S3A versus WPD from ECMWF (top) and GPD1 (bottom), in cm; (Right panels): WPD from S3A versus WPD difference between ECMWF and S3A (top) and between GPD1 and S3A (bottom).

Aiming at inspecting the impact of the S3A WTC on the computation of SRAL-derived sea level anomalies in comparison with other WTC such as ECMWF, GPD1, and GPD2, various SLA variance analyses have been performed that can be divided into: (1) SLA along-track variance differences (weighted mean values per cycle and at collocated points, function of distance from coast and function of latitude); and (2) SLA analysis at crossovers (weighted mean cycle values and spatial pattern).

For this purpose, SLA datasets are first derived, for each S3A cycle, using the different WTC under comparison, a pair each time being compared. Then, for case (1), the difference between the weighted variance of each SLA dataset, computed using all along-track points, is estimated for each cycle. In addition, for the analysis of the SLA variance difference function of the distance from coast and function of latitude, the variance of co-located along-track SLA measurements for the whole study period and using each WTC is computed in bins of distance from the coast or latitude, respectively, and the differences are computed. For case (2), crossovers are first estimated using a pair of SLA datasets each time and the weighted variance of SLA differences is computed at cross-over points and estimated for each cycle. Moreover, the variances of the SLA differences at crossovers are computed in regular latitude $\times$ longitude grids $\left(4^{\circ} \times 4^{\circ}\right)$ and subtracted. Crossovers with a time difference less than 14 days, the minimum period to obtain S3A crossovers at all latitude bands, have been considered.

The results are shown in Figures 17-21, their discussion being described in Section 4.

The S3A products used in this study also include the composite WTC. Although [26] indicates that this correction is still not calibrated, a first assessment is also included here. Figure 22 depicts some representative examples of S3A passes where this WTC is compared against those from ECMWF, the MWR, and GPD2, showing that the present implementation of this correction evidences significant problems. 

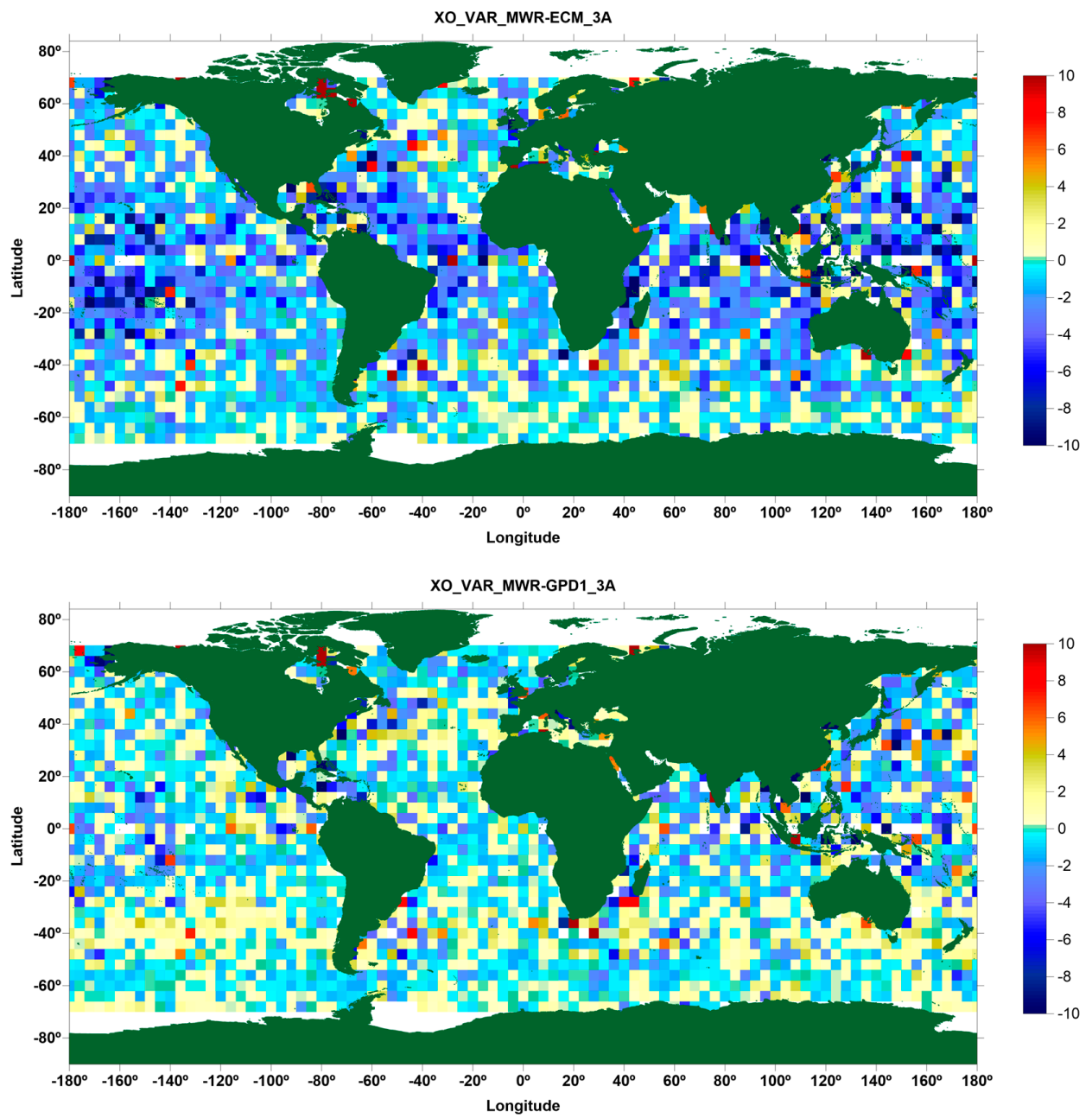

Figure 17. Spatial distribution of the weighted sea level anomaly (SLA) variance differences at crossovers, for SLA datasets computed using the MWR- and ECMWF-derived WTC (Top) and those using the WTC from the MWR and GPD1 (Bottom) for the period corresponding to S3A cycles 05 to 16. Only points with valid observations have been used.

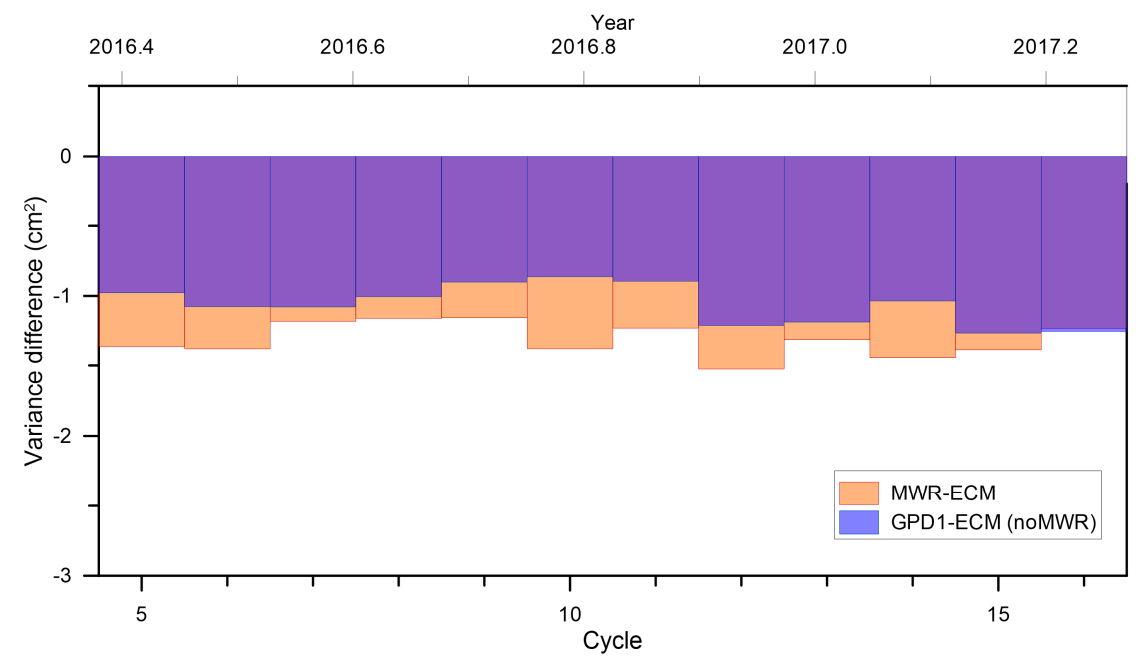

Figure 18. Cont. 


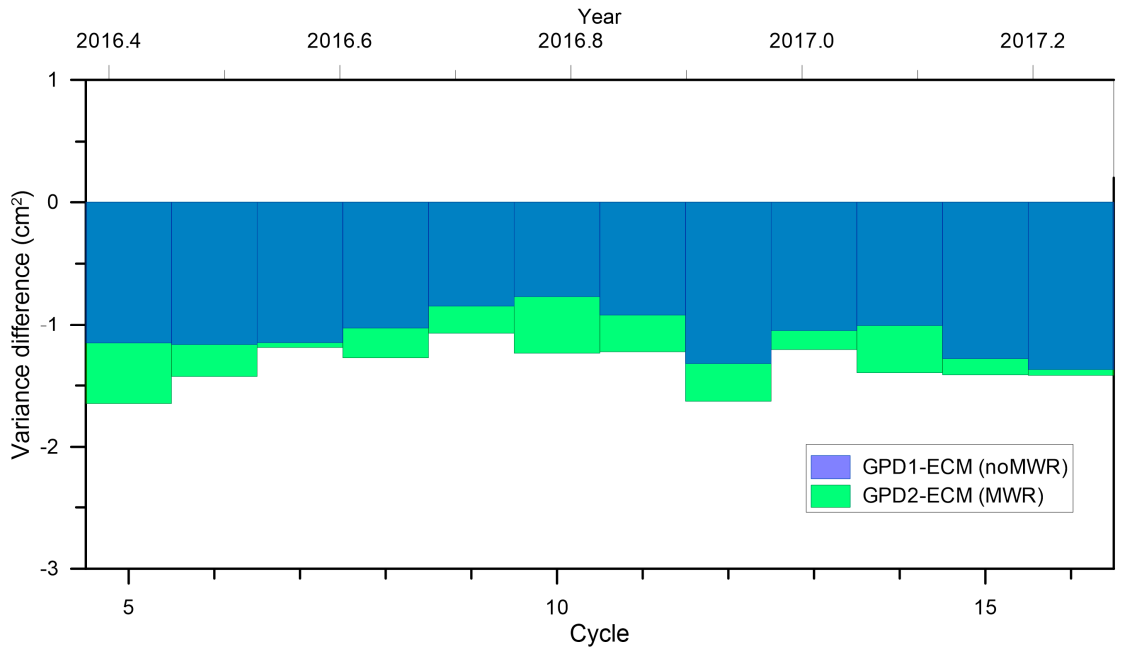

Figure 18. (Top panel): temporal evolution of weighted SLA variance differences at crossovers for SLA datasets computed using the WTC from the S3A MWR and ECMWF (orange) and the WTC from GPD1 and ECMWF (blue) using only points with a valid MWR; (Bottom panel): temporal evolution of weighted SLA variance differences at crossovers between SLA datasets computed using the WTC from GPD1 and that from ECMWF (blue) and between GPD2 and ECMWF (green), using all points with valid SLA.
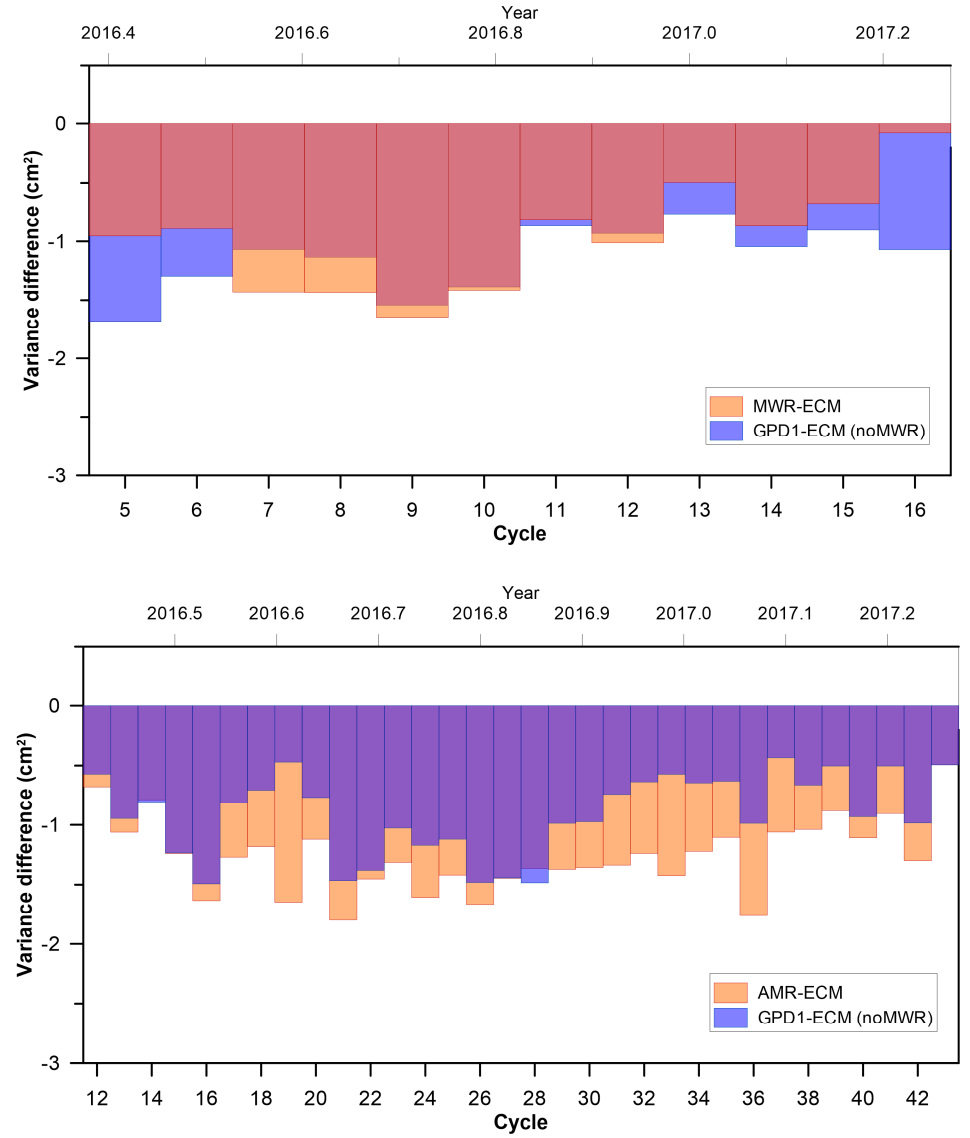

Figure 19. Temporal evolution of weighted along-track SLA variance differences for SLA datasets computed using the WTC from the on-board MWR and from ECMWF (orange) and those from GPD1 and ECMWF (blue) for S3A (Top) and J3 (Bottom). Only points with a valid MWR have been used. 

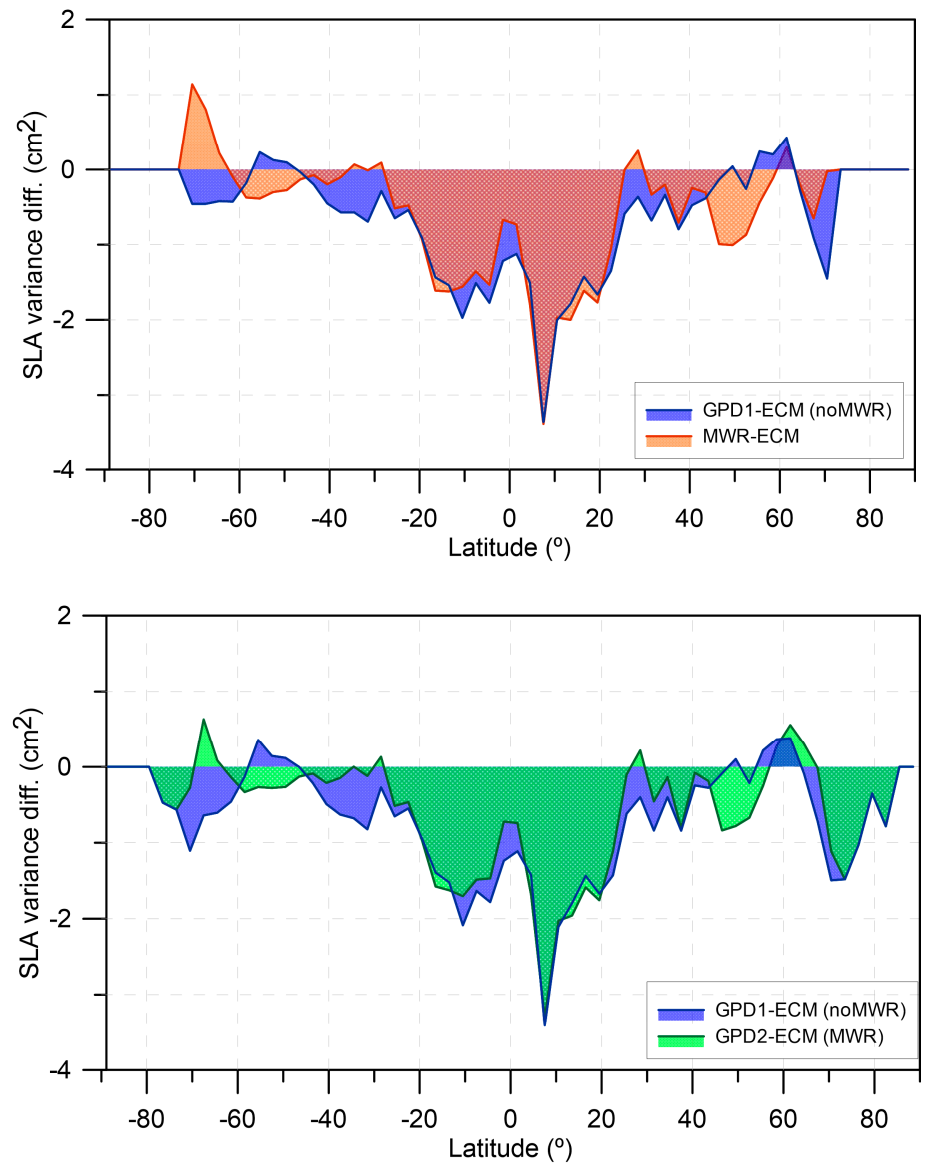

Figure 20. (Top panel): variance differences of SLA versus latitude, for SLA datasets computed using the WTC from the MWR and ECMWF (orange) and those from GPD1 and ECMWF (blue), over the period of S3A cycles 05 to 16 and using only points with a valid MWR; (Bottom panel): variance differences of SLA versus latitude between GPD1 and ECMWF (blue) and between GPD2 and ECMWF (green), over the period of S3A cycles 05 to 16 using all points with valid SLA.

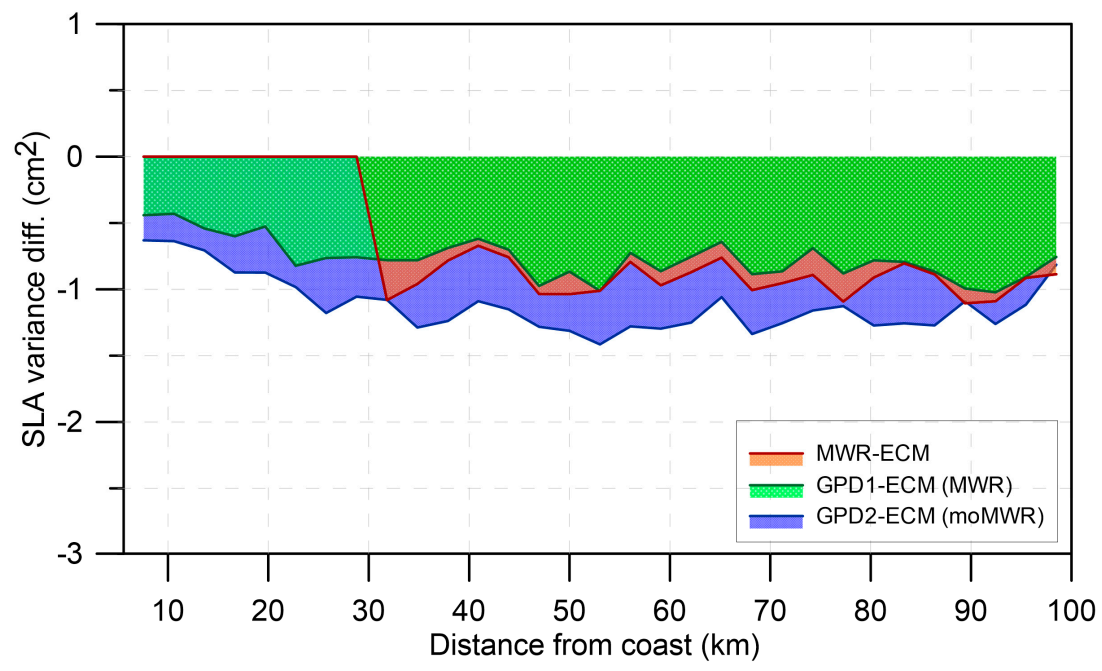

Figure 21. Variance differences of SLA versus distance from coast for SLA datasets computed using the WTC from MWR and ECMWF (orange), those from GPD1 and ECMWF (blue) and those from GPD2 and ECMWF (green) over the period of S3A cycles 05 to 16. In the first case only valid MWR points were selected while in the last two cases all points with valid SLA were considered 

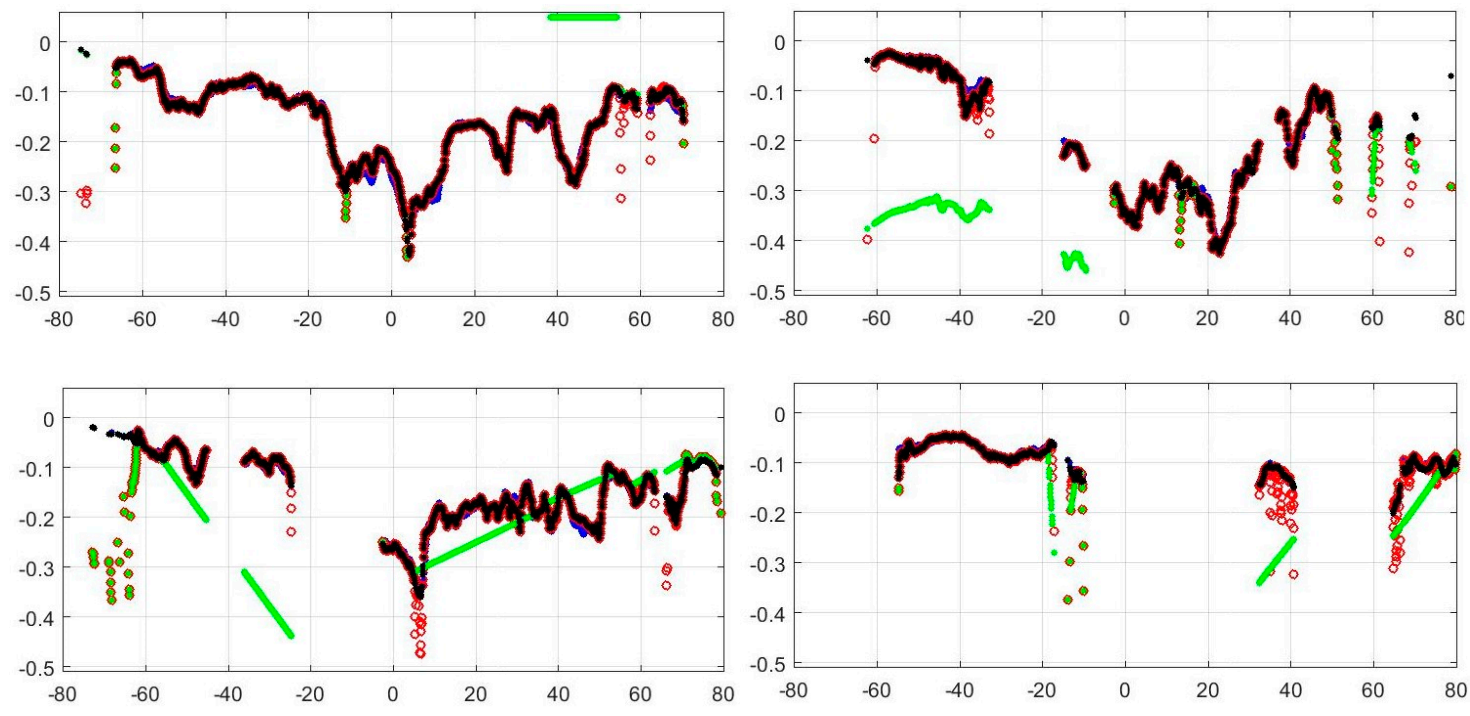

Figure 22. From top to bottom and left to right: WTC (in metres) for S3A cycle 06 passes 041, 646, 660, and 670, as a function of latitude (degrees). Shown are: ECMWF Operational (blue), MWR (red), GPD2 (black), and composite (green) WTC.

\section{Discussion}

This section presents a thorough discussion of the results presented in Section 3.

In terms of the global statistical parameters, GMI and Sentinel-3A agree very well, with mean and RMS of WPD differences (WPD(GMI)-WPD(S3A)) of $0.17 \mathrm{~cm}$ and $0.95 \mathrm{~cm}$, respectively. The overall pattern of the WPD differences at match points shown in Figure 3 seems to indicate that at the low latitudes, where the WPD is larger, GMI measures wetter than S3A, while at the extreme southern latitudes, corresponding to regions of low WPD values, there is a tendency for GMI to measure drier than S3A. However, the scale factor $(1.004)$ and small offset $(0.12 \mathrm{~cm})$ reveal a very good overall match between the two sensors, also demonstrated by the very small scatter of the scatter plot of the two WPDs illustrated in Figure 4.

The most curious feature of the comparison between GMI and S3A is the observed strong periodic pattern of 41 days. When analysing the way the spatial pattern of the match points changes with time (Figures 5 and 6), it can be observed that there are periods for which all match points between the two sensors are located only at high latitudes. An example of these periods is the one corresponding to the green bar in Figure 5, to which the points with the same green colour in Figure 7 (all above latitude $50^{\circ} \mathrm{N}$ or below latitude $50^{\circ} \mathrm{S}$ ) correspond. During these periods, since the WPD at high latitudes is low (only a few $\mathrm{cm}$ ) and with low variability, the differences between the two sensors are very small, with absolute values of less than $1 \mathrm{~cm}$. On the contrary, during periods such as the one corresponding to the orange bar in Figure 5, the match points are located at the low latitudes, between $\pm 50^{\circ}$ (orange points in Figure 6). Over these periods, the WPD reaches higher values (up to $40-50 \mathrm{~cm}$ ) and has larger variability, inducing larger differences between the two sensors. These results are a clear demonstration of the impact of data sampling in this type of study, which, if not properly accounted for, can lead to misinterpretations.

The authors of [26] report that the S3A MWR L1 brightness temperatures exhibit a difference of up to $1 \mathrm{~K}$ between ascending and descending tracks for the 23.8- $\mathrm{GHz}$ channel, with unknown origin. With a view to investigate if this potential bias can be observed in the current L2 products, the differences WPD (GMI) - WPD(S3A) have been represented in the bottom panel of Figure 5 separately for ascending (in blue) and descending (in red) tracks. No significant differences can be observed between the ascending and descending track differences. In terms of overall statistics, the S3A WPD differences with respect to GMI for the ascending tracks are about $1 \mathrm{~mm}$ larger than 
those for the descending tracks (compare dark blue with dark red lines in the bottom panel of Figure 5). This difference is too small, insignificant and cannot be related with the reported $1 \mathrm{~K}$ difference since the latter can lead to WPD differences ranging from $0.2 \mathrm{~cm}$ to $1 \mathrm{~cm}$.

In spite of the small analysis period, the RMS differences (between GMI and S3A) computed for periods of the S3A cycles (27-day) evidence a long-term stable signal with an 82-day periodic pattern. This pattern occurs due to the fact that S3A orbit is Sun-synchronous, while GPM orbit is not. Due to its orbit characteristics, the GPM orbital plane takes 82 days to complete a full rotation with respect to the Sun and therefore with respect to the S3A orbital plane, explaining the observed periodic signal. In spite of these periodicities observed in the differences between GMI and the S3A MWR, due to the fact that GMI is on a non-Sun-synchronous orbit with a $65^{\circ}$ inclination, the number of match points with S3A is larger than for example with any SSM/IS sensor, as these are on Sun-synchronous orbits, out of phase with respect to the S3A orbit by 3-6 h.

The comparison with the radiometers on board J2 and J3 indicate that on average these sensors measure drier than S3A by about $0.6-0.7 \mathrm{~cm}$, while the RMS of the differences is within $1.2-1.3 \mathrm{~cm}$. The scale factor (1.01), the negative offset of -0.7 and $-0.8 \mathrm{~cm}$ and the blue predominant colour in the spatial pattern of the WPD differences shown in the top and medium panels of Figure $8 \mathrm{confirm}$ this tendency.

For SARAL, the results are a bit different. The RMS of the differences is larger $(1.5 \mathrm{~cm})$ which can be explained by the fact that the crossover differences span a larger time interval ( 240 min versus $180 \mathrm{~min}$ used for J2 and J3). The scale factor of 0.96 , offset of $0.6 \mathrm{~cm}$, and the larger scatter observed in Figure 8 (bottom panel) and 9 (bottom panel) indicate a slightly larger difference between these two sensors, partly explained by the mentioned time difference between the corresponding crossovers.

The statistical parameters of the comparisons between S3A and the MWR aboard the other three altimeter missions are in agreement with the results presented in [24] and further work by these authors, comparing the same sensors with the SSM/I and SSM/IS sensors, which also indicate that J2 and $\mathrm{J} 3$ measure drier than the latter sensors by about $0.6 \mathrm{~cm}$ and $1 \mathrm{~cm}$, respectively.

The time evolution of the daily and 27-day RMS differences between J2, J3, SARAL, and S3A illustrated in Figure 10 indicates a stable behaviour of the Sentinel-3A radiometer with respect to these sensors.

The comparisons with WTC derived at coastal GNSS stations show that land contamination can be observed in the S3A MWR observations up to $20-25 \mathrm{~km}$ from the coast. At this distance, the RMS of the differences between the WTC from S3A and the GNSS-derived ZWD is about $1.8 \mathrm{~cm}$, increasing rapidly towards the coast, a clear indication that in the band of $0 \mathrm{~km}$ up to $25 \mathrm{~km}$ the MWR observations are not valid. On the contrary, no land contamination can be observed in the GPD1 WTC, derived solely from third party data. This stresses the need for robust criteria to remove the land-contaminated MWR observations and the important role of solutions such as GPD+ in providing valid WTC in the coastal regions.

Section 3.3 presents an extensive comparison between the S3A WTC and various corrections: GPD1 (from the GPD+ algorithm using only third party data), GPD2 (from the GPD+ algorithm, preserving the valid S3A MWR observations), the ECMWF operational model, and the composite WTC. In Figures 12 and 13, it can be observed that GPD1 and GPD2 are very similar, in spite of the fact that GPD1 does not use any observations from the S3A on-board MWR. It can also be concluded that, in regions with a valid MWR, the ECMWF operational model values are also very close, the main difference being that some, though important, small scale features are missing. These figures are clear illustration of typical S3A MWR-derived WTCs, where invalid observations can be observed near the coast, at high latitudes and at low latitudes, associated with heavy rain events.

The spatial distribution of the RMS of WPD differences between GPD1 and S3A MWR for the whole period of study (cycles 05 to 16), shown in Figure 14, indicates that the largest differences between these two WTCs are associated with regions with the largest WTC variability and ocean circulation patterns. Large differences also occur in some coastal regions, a possible indicator that 
some noisy MWR observations may still be present, in spite of the fact that all MWR measurements at distances from coast less than $30 \mathrm{~km}$ have been removed.

Both the statistical parameters in Table 1 and Figure 16 evidence that the S3A WPD is closer to GPD1 (RMS difference less than $1 \mathrm{~cm}$ ) than to the ECMWF model (RMS difference $1.3 \mathrm{~cm}$ ). The mean values of these differences are very small $(0.1 \mathrm{~cm}$ and $0.2 \mathrm{~cm}$ for the comparison with GPD1 and ECMWF, respectively). The scale factors are both 1.01 and the offsets are also very small $(0.2 \mathrm{~cm}$, $-0.1 \mathrm{~cm}$ ). The time evolution of these differences, shown as 27-day RMS values in Figure 15, is stable.

The better agreement of S3A MWR-derived WTC with GPD1 in comparison with the ECMWF model is also observed in the scatterplots of Figure 16, where a smaller scatter can be observed for the former WTC pair. The better agreement of the S3A MWR with GPD1 than with the ECMWF model is explained by the fact that GPD1 WTC is also based on observations and the model has a poor temporal sampling of $6 \mathrm{~h}$.

Figures 17-21 present the assessment of the S3A MWR-based WTC by means of SLA variance analysis. In this analysis, the WTC from S3A MWR, GPD1, and GPD2 are compared against the ECMWF model. In this way, both the performance of each WTC with respect to this model and their relative performance can be analysed.

The SLA variance analysis at crossovers presented in Figures 17 and 18 indicates that the S3A MWR reduces the variance both with respect to ECMWF and GPD1 (Figure 18, top panel), the first reduction being significant (mean cycle values of $1.1-1.5 \mathrm{~cm}^{2}$ ), while the latter (not shown, inferred from Figure 18, top panel) is quite small (mean cycle values of $0.1-0.3 \mathrm{~cm}^{2}$ ). The same is observed when comparing the performance of GPD1 and GPD2 against ECMWF (Figure 18, bottom panel). GPD1 reduces the mean cycle variance by $0.8-1.4 \mathrm{~cm}^{2}$ while GPD2 reduces by $1.0-1.6 \mathrm{~cm}^{2}$. Note that the comparisons involving the MWR only use the valid MWR points, while the comparisons involving only GPD1 and GPD2 use all points with valid SLA.

While the results from the variance analysis at crossovers indicate that the S3A MWR consistently reduces the SLA variance with respect to the WTC that only incorporates non-collocated radiometers (GPD1) and that the latter increases the variance with respect to the GPD+ WTC that makes use of the S3A MWR (GPD2), the same does not happen in along-track SLA variance analysis. In the along-track SLA variance differences, computed cycle by cycle (Figure 19), in most cycles GPD1 leads to a slightly larger SLA variance reduction with respect to ECMWF than the GPD WTC that incorporates the S3A MWR (GPD2). This is also demonstrated in Figures 20 and 21, which present the along-track variance differences in function of latitude and distance from coast, respectively. The top panel of Figure 20 shows that, in comparison with the MWR, GPD1 conducts to a slightly larger variance reduction with respect to ECMWF, except for some high-latitude bands. The bottom panel of the same figure shows that, in comparison with GPD2, with the exception of some high latitude bands, GPD1 also leads to a slightly larger SLA variance reduction with respect to ECMWF. In the first comparison only valid MWR points have been used, while in the latter all points with valid SLA have been analysed. This result is more evident in the SLA variance analysis function of distance from coast (Figure 21) where GPD1 consistently reduces the variance with respect to both MWR and GPD2.

This result is not expected since, in all previous analyses performed by the authors, the WTC derived from observations of the on-board MWR always reduced the SLA variance with respect to the WTC that only uses non-collocated observations, in all types of diagnoses and when only valid MWR points are selected. As an example, the bottom panel of Figure 19 illustrates for J3 the same variance analysis shown in the top panel for S3A, for the same period, proving that, contrary to S3A, the J3 AMR-2 WTC is consistently better than that of GPD1. Similar results have been obtained for Envisat, confirming that the GPD+ WTC that incorporates the valid observations from the Envisat radiometer consistently reduces the SLA variance with respect to the correction that only uses third party observations. These results indicate that although the overall performance of the S3A MWR seems good, improvements are still required to retrieve a WTC with the quality of that for J3. 
In the latitude plots (Figure 20) some ice contamination can still be observed in the MWR-derived WTC and GPD2, suggesting that more robust editing is still desirable in the polar regions. We recall that a strong editing has already been performed by rejecting all MWR observations above latitude $70^{\circ} \mathrm{N}$ and below $70^{\circ} \mathrm{S}$. Consequently, the preliminary version of the GPD+WTC that makes use of the on-board MWR (GPD2) can still be improved, even with the present MWR dataset.

The examination of the composite correction present on the analysed S3A products shows that the implementation of this WTC still has serious problems, depicted in Figure 22. Moreover, the correction is not present in a large percentage of points, e.g., $21 \%$ of the points with valid SLA for cycle 06. Similar to the GPD+ WTC, the composite WTC aims at generating a continuous correction, valid everywhere, including the coastal zones and high latitudes. Also, similar to the GPD2 type of correction described in this paper, it also preserves the valid MWR values. The main difference between GPD+ and the composite WTC is that, on every invalid point, the former retrieves a new estimate by data combination of all available observations, while the latter uses the model values, adjusted to the closest valid MWR points. This requires robust criteria to detect valid/invalid MWR values, otherwise the model will be adjusted to spurious MWR observations, resulting in large biases as shown e.g., in the bottom left panel of Figure 22 or straight lines as shown in the right panels of the same figure. Similar behaviour has been observed, though in only a few occurrences, in the composite correction present in the Archiving, Validation and Interpretation of Satellite Oceanographic data (AVISO) Corrected Sea Surface Heights (CORSSH) products of TOPEX/Poseidon [23]. Due to potential implementation problems and the fact that GPD+ use observations while the composite is solely based on model values, it has been shown that the GPD type of WTC is a significant improvement with respect to the composite WTC, particularly in the coastal zone $[9,23]$.

\section{Conclusions}

This study presents an independent assessment of the wet tropospheric correction derived from the two-band microwave radiometer deployed on Sentinel-3A, present on the L2 NTC products from the "Spring 2017" Reprocessing Campaign", Processing Baseline 2.15.

Studies such as this one play an important role in the improvement of altimeter-derived products, as satellite-derived data improvement is a long and continuous process. Sentinel-3 is a challenging mission in many aspects, with the research community having a long way to go to fully exploit the capabilities of its instruments, in particular SRAL. Six years after its end of mission, Envisat data are still being reprocessed and the reprocessing of TOPEX/Poseidon data has been delayed for several years.

Considering the relatively short time span of the dataset (10 months), the overall performance of the S3A MWR seems stable, with no drifts or irregular behaviour having been observed. A pronounced periodic signal has been observed in the differences with respect to GMI, due to the orbit configurations of the spacecraft housing these sensors.

When considering the linear adjustment of S3A MWR-derived WPD to those from four different sensors, scale factors very close to 1 have been obtained: GMI (1.00); J2 and J3 (1.11); and SARAL (0.96). The corresponding values for the WTC are the same since WTC is symmetric to WPD. All WPD offsets have absolute values of less than $1 \mathrm{~cm}$ : GMI $(0.1 \mathrm{~cm}), \mathrm{J} 2(-0.7 \mathrm{~cm}), \mathrm{J} 3(-0.8 \mathrm{~cm})$, and SARAL $(0.6 \mathrm{~cm})$. The corresponding offsets for the WTC are symmetric to those for WPD. The mean WPD differences have absolute values below $1 \mathrm{~cm}$ : GMI $(0.2 \mathrm{~cm}), \mathrm{J} 2(-0.6 \mathrm{~cm}), \mathrm{J} 3(-0.7 \mathrm{~cm})$ and SARAL $(0.0 \mathrm{~cm})$, the mean WTC differences being the corresponding symmetric values. RMS WPD (or WTC) differences (cm) of 0.95 (GMI), 1.3 (J2), 1.3 (J3), and 1.5 (SARAL) demonstrate a good agreement with all these sensors, in particular with GMI.

The comparison with GNSS shows land contamination in the S3A MWR observations up to 20-25 km and RMS differences between S3A MWR WTC and GNSS-derived ZWD of $1.8 \mathrm{~cm}$ at these distances. These results are in agreement with those found for the radiometers of other altimetric missions, for which the corresponding RMSs of differences are 1.7-1.8 cm [43]. 
Extensive comparison has been performed with the ECMWF model-derived WTC and two WTC versions from the GPD+ algorithm: one using only third party data (GPD1) and another preserving the valid S3A MWR points (GPD2). Direct WTC comparisons show small statistical parameters for the differences between all these corrections. As expected, smaller RMS values have been observed for the differences with respect to the GPD+ WTC (1 cm for GPD1) than for the differences with respect to ECMWF $(1.3 \mathrm{~cm})$. The scale factors with respect to both GPD1 and ECMWF are 1.01 and both offsets and mean differences have absolute values smaller than or equal to $0.2 \mathrm{~cm}$.

As expected, all SLA variance analyses evidence a reduction of $1-2 \mathrm{~cm}^{2}$ of the SLA computed with the S3A MWR WTC with respect to the ECMWF model, when mean cycle values are considered. The SLA variance analysis at crossover points indicates a small (mean cycle values less than $0.5 \mathrm{~cm}^{2}$ ) but consistent variance reduction with respect to GPD1, however, the opposite is observed in the along-track variance analysis. This seems to suggest that improvements in both the retrieval algorithm and the criteria used to detect valid/invalid MWR observations are required to achieve a WTC with accuracy similar to the AMR-2 WTC for Jason-3. These results also highlight that the along-track comparison with the GPD1 type of WTC provides complementary and very important insight into the quality of the S3A MWR-derived WTC, not evident in the assessment against the other.

Similar to other dual-frequency radiometers on board the previous ESA missions, strong ice and land contamination is observed, the former in particular making the establishment of validation criteria for the MWR observations difficult at the high latitudes. Consequently, all observations with latitude absolute values larger than $70^{\circ}$ have been rejected.

The composite WTC present in the analysed products was revealed to have implementation problems and was unsuitable for use, improvements being required in future versions of S3A data.

As a whole, this study contributes to a better knowledge of the wet path delay affecting satellite altimeter observations. In spite of the good overall performance of the S3A MWR when compared against other state-of-the-art radiometers, current limitations are also identified. Once a tuned retrieval algorithm is achieved, meeting the state-of-the art performances of current and past similar instruments, the inability of this type of radiometer to measure over non-ocean surfaces such as e.g., land, ice, or wetlands, prevent its use in these regions. Therefore, in regions where accurate satellite altimetry measurements are of crucial importance such as coastal or inland water zones, and accurate MWR-derived WTC retrieval is not possible, alternative methods such as the GPD+ type of corrections must be used.

The GPD+ WTC solely based on third-party observations, together with microwave radiometers on board other altimeter missions and GMI, were revealed to be very useful and independent tools to validate the Sentinel-3 radiometer-based wet tropospheric correction. Future work includes the monitoring of upcoming versions of this dataset and generation of updated versions of the GPD+ WTC making use of ameliorated MWR data, which will contribute to the generation of an accurate version of this important range correction for S3A SRAL measurements over the whole ocean, including coastal zones and at high latitudes.

In regions such as coastal and continental water zones, radiometers with additional high-frequency channels, such as the one being built for Jason-CS/Sentinel-6 [51] will provide smaller footprints, of great relevance for resolution of smaller scales of variability of the WTC.

Over inland water regions and to some extent in coastal regions, the availability of tropospheric corrections at high rate (frequency higher than $1 \mathrm{~Hz}$ ), either from radiometers with smaller footprints or from high-resolution atmospheric models is also of great relevance, in particular in the exploitation of Sentinel-3 high-rate altimeter data. The advantage of having range corrections at a high rate applies not only to the WTC but also to the dry component of the tropospheric path delay, the dry tropospheric correction (DTC). In regions of sharp topography variations such as some steep coastal regions, lakes or rivers, one of the factors with most impact on the retrieval of accurate tropospheric corrections is their height dependence, particularly large for the DTC (1 cm per $40 \mathrm{~m}$ of height variation) [13]. 
The future of tropospheric corrections for satellite altimetry includes: WTC from MWRs with additional high-frequency channels and improved retrieval algorithms (over the open and coastal ocean and over lakes); and WTC and DTC from high-resolution atmospheric models, both computed at surface height using accurate Digital Elevation Models (DEM) or the altimeter-measured surface height (over inland water regions). In all cases, high-rate (e.g., $20 \mathrm{~Hz}$ ) corrections are desirable to better account for spatial variability of km order or less, in particular the variability associated with the surface height variations.

Acknowledgments: This work was supported by the European Space Agency in the scope of the SAR Altimetry Coastal and Open Ocean-Performance Exploitation and Roadmap Study (SCOOP) project, Subcontract to SCOOP Contract N. 4000115385/15/I-BG. It is also a contribution to the Validation of Coastal ALtimetry from Sentinel-3 (VOCALS3) project. The authors would like to thank RADS for providing the S3A data, Remote Sensing Systems for providing the GMI products, and the European Centre for Medium-Range Weather Forecasts (ECMWF) for making the ECMWF operational model available.

Author Contributions: M.J.F. conceived, designed and performed the experiments and wrote the paper; C.L. contributed to data analysis editing and review of the paper.

Conflicts of Interest: The authors declare no conflicts of interest.

\section{References}

1. Benveniste, J. Radar altimetry: Past, present and future. In Coastal Altimetry; Vignudelli, S., Kostianoy, A., Cipollini, P., Benvensite, J., Eds.; Springer: Berlin/Heidelberg, Germany, 2011.

2. Stammer, D.; Cazenave, A. Satellite Altimetry over Oceans and Land Surfaces, 1st ed.; CRC Press: Boca Raton, FL, USA, 2017.

3. Le Traon, P.Y. From satellite altimetry to argo and operational oceanography: Three revolutions in oceanography. Ocean Sci. 2013, 9, 901-915. [CrossRef]

4. Le Traon, P.Y.; Dibarboure, G.; Jacobs, G.; Martin, M.; Remy, E.; Schiller, A. Use of satellite altimetry for operational oceanography. In Satellite Altimetry over Oceans and Land Surfaces; Stammer, D., Cazenave, A., Eds.; CRC Press: Boca Raton, FL, USA, 2017.

5. Ablain, M.; Cazenave, A.; Larnicol, G.; Balmaseda, M.; Cipollini, P.; Faugere, Y.; Fernandes, M.J.; Henry, O.; Johannessen, J.A.; Knudsen, P.; et al. Improved sea level record over the satellite altimetry ERA (1993-2010) from the climate change initiative project. Ocean Sci. 2015, 11, 67-82. [CrossRef]

6. Ablain, M.; Legeais, J.F.; Prandi, P.; Marcos, M.; Fenoglio-Marc, L.; Dieng, H.B.; Benveniste, J.; Cazenave, A. Satellite altimetry-based sea level at global and regional scales. Surv. Geophys. 2017, 38, 7-31. [CrossRef]

7. Quartly, G.D.; Legeais, J.F.; Ablain, M.; Zawadzki, L.; Fernandes, M.J.; Rudenko, S.; Carrère, L.; García, P.N.; Cipollini, P.; Andersen, O.B.; et al. A new phase in the production of quality-controlled sea level data. Earth Syst. Sci. Data 2017, 9, 557-572. [CrossRef]

8. Nerem, R.S.; Ablain, M.; Cazenave, A.; Church, J.; Leuliette, E. A 25-year satellite altimetry-based global mean sea level record: Closure of the sea level budget and missing components. In Satellite Altimetry over Oceans and Land Surfaces; Stammer, D., Cazenave, A., Eds.; CRC Press: Boca Raton, FL, USA, 2017.

9. Legeais, J.F.; Ablain, M.; Zawadzki, L.; Zuo, H.; Johannessen, J.A.; Scharffenberg, M.G.; Fenoglio-Marc, L.; Fernandes, M.J.; Andersen, O.B.; Rudenko, S.; et al. An accurate and homogeneous altimeter sea level record from the esa climate change initiative. Earth Syst. Sci. Data 2017, 2017, 1-35. [CrossRef]

10. Birkett, C.; Reynolds, C.; Beckley, B.; Doorn, B. From research to operations: The usda global reservoir and lake monitor. In Coastal Altimetry; Vignudelli, S., Kostianoy, A.G., Cipollini, P.J.B., Eds.; Springer-Verlag: Berlin/Heidelberg, Germany, 2011.

11. Cretaux, J.-F.; Nielsen, K.; Frappart, F.; Papa, F.; Calmant, S.; Benveniste, J. Hydrological applications of satellite altimetry: Rivers, lakes, man-made reservoirs, inundated areas. In Satellite Altimetry in Coastal Regions; CRC Press: Boca Raton, FL, USA, 2017.

12. Remy, F.; Memin, A.; Velicogna, I. Applications of satellite altimetry to study the antarctic ice sheet, satellite altimetry in coastal regions. In Satellite Altimetry over Oceans and Land Surfaces, 1st ed.; Stammer, D., Cazenave, A., Eds.; CRC Press: Boca Raton, FL, USA, 2017; p. 670.

13. Fernandes, M.J.; Lazaro, C.; Nunes, A.L.; Scharroo, R. Atmospheric corrections for altimetry studies over inland water. Remote Sens. 2014, 6, 4952-4997. [CrossRef] 
14. Chelton, D.B.; Ries, J.C.; Haines, B.J.; Fu, L.L.; Callahan, P.S. Satellite altimetry. In Satellite Altimetry and Earth Sciences: A Handbook of Techniques and Applications; Fu, L.L., Cazenave, A., Eds.; Academic Press: San Diego, CA, USA, 2001.

15. Vieira, T.; Fernandes, M.J.; Lázaro, C. Analysis and retrieval of tropospheric corrections for cryosat-2 over inland waters. Adv. Sp. Res. 2017, 46. [CrossRef]

16. Cipollini, P.; Benveniste, J.; Birol, F.; Fernandes, M.J.; Obligis, E.; Passaro, M.; Strub, P.T.; Valladeau, G.; Vignudelli, S.; Wilkin, J. Satellite altimetry in coastal regions. In Satellite Altimetry over Oceans and Land Surfaces, 1st ed.; Stammer, D., Cazenave, A., Eds.; CRC Press: Boca Raton, FL, USA, 2017.

17. Keihm, S.J.; Janssen, M.A.; Ruf, C.S. Topex/poseidon microwave radiometer (TMR). III. Wet troposphere range correction algorithm and pre-launch error budget. IEEE Trans. Geosci. Remote Sens. 1995, 33, 147-161. [CrossRef]

18. Eymard, L.; Obligis, E. The Altimetric Wet Troposheric Correction: Progress Since the ERS-1 Mission. In Proceedings of the15 Years of Progress in Radar Altimetry, Venice, Italy, 13-18 March 2006.

19. Tournadre, J.; Lambin-Artru, J.; Steunou, N. Cloud and rain effects on altika/saral ka-band radar altimeter-part i: Modeling and mean annual data availability. IEEE Trans. Geosci. Remote Sens. 2009, 47, 1806-1817. [CrossRef]

20. Sentinel-3 Team. Sentinel-3 User Handbook, 2nd ed.; GMES-S3OP-EOPG-TN-13-0001; European Space Agency: Paris, France, 2013.

21. Dinardo, S.; Fenoglio-Marc, L.; Buchhaupt, C.; Becker, M.; Scharroo, R.; Joana Fernandes, M.; Benveniste, J. Coastal sar and plrm altimetry in german bight and west baltic sea. Adv. Sp. Res. 2017. [CrossRef]

22. Tournadre, J. Improved level-3 oceanic rainfall retrieval from dual-frequency spaceborne radar altimeter systems. J. Atmos. Ocean. Technol. 2006, 23, 1131-1149. [CrossRef]

23. Fernandes, M.J.; Lazaro, C.; Ablain, M.; Pires, N. Improved wet path delays for all esa and reference altimetric missions. Remote Sens. Environ. 2015, 169, 50-74. [CrossRef]

24. Fernandes, M.J.; Lazaro, C. Gpd+ wet tropospheric corrections for cryosat-2 and gfo altimetry missions. Remote Sens. 2016, 8, 851. [CrossRef]

25. EUMETSAT, S3a STM Reprocessing-“Spring 2017” (Level 0 to Level 2). Available online: eum/ops-sen3/ rep/17/940906 (accessed on 31 August 2017).

26. EUMETSAT, Sentinel-3a Product Notice-STM 12 Marine ("Spring Reprocessing Campaign”). Available online: um/ops-sen3/doc/17/944329 (accessed on 15 September 2017).

27. Scharroo, R.; Leuliette, E.; Naeije, M.; Martin-Puig, C.; Pires, N. Rads Version 4: An efficient way to analyse the Multi-Mission altimeter database. In Proceedings of the ESA Living Planet Symposium, Prague, Czech Republic, 9-13 May 2016; ESA: Prague, Czech Republic, 2016.

28. Obligis, E.; Eymard, L.; Tran, N.; Labroue, S.; Femenias, P. First three years of the microwave radiometer aboard envisat: In-flight calibration, processing, and validation of the geophysical products. J. Atmos. Ocean. Technol. 2006, 23, 802-814. [CrossRef]

29. Thao, S.; Eymard, L.; Obligis, E.; Picard, B. Comparison of regression algorithms for the retrieval of the wet tropospheric path. IEEE J. Sel. Top. Appl. Earth Obs. Remote Sens. 2015, 8, 4302-4314. [CrossRef]

30. Collecte Localisation Satellites (CLS). Surface Topography Mission (STM) Sral/Mwr L2 Algorithms Definition, Accuracy and Specification; S3PAD-RS-CLS-SD03-00017; CLS: Ramonville St-Agne, France, 2011.

31. Mercier, F.; Rosmorduc, V.; Carrère, L.; Thibaut, P. Coastal and Hydrology Altimetry Product (PISTACH) Handbook. 2010. Available online: https://www.aviso.altimetry.fr/fileadmin/documents/data/tools/ hdbk_Pistach.pdf (accessed on 19 March 2018).

32. Meissner, T.; Wentz, F.J.; Draper, D. Gmi Calibration Algorithm and Analysis Theoretical Basis Document; Report Number 041912; Remote Sensing Systems: Santa Rosa, CA, USA, 2012; 124p.

33. Draper, D.W.; Newell, D.A.; Wentz, F.J.; Krimchansky, S.; Skofronick-Jackson, G.M. The global precipitation measurement (GPM) microwave imager (GMI): Instrument overview and early on-orbit performance. IEEE J. Sel. Top. Appl. Earth Obs. Remote Sens. 2015, 8, 3452-3462. [CrossRef]

34. Fernandes, M.J.; Nunes, A.L.; Lazaro, C. Analysis and inter-calibration of wet path delay datasets to compute the wet tropospheric correction for cryosat-2 over ocean. Remote Sens. 2013, 5, 4977-5005. [CrossRef]

35. Stum, J.; Sicard, P.; Carrere, L.; Lambin, J. Using objective analysis of scanning radiometer measurements to compute the water vapor path delay for altimetry. IEEE Trans. Geosci. Remote Sens. 2011, 49, 3211-3224. [CrossRef] 
36. Wentz, F.J. A well-calibrated ocean algorithm for special sensor microwave/imager. J. Geophys. Res. Oceans 1997, 102, 8703-8718. [CrossRef]

37. Wentz, F.J. SSM/I Version-7 Calibration Report; RSS Technical Report 011012; Remote Sensing Systems: Santa Rosa, CA, USA, 2013; p. 46.

38. Brown, S. A novel near-land radiometer wet path-delay retrieval algorithm: Application to the Jason-2/OSTM advanced microwave radiometer. IEEE Trans. Geosci. Remote Sens. 2010, 48, 1986-1992. [CrossRef]

39. Dumont, J.P.; Rosmorduc, V.; Picot, N.; Bronner, E.; Desai, S.; Bonekamp, H.; Figa, J.; Lillibridge, J.; Scharroo, R. OSTM/Jason-2 Products Handbook. 2011. Available online: http://www.ospo.noaa.gov/ Products/documents/J2_handbook_v1-8_no_rev.pdf (accessed on 19 March 2018).

40. Dumont, J.P.; Rosmorduc, V.; Carrere, L.; Picot, N.; Bronner, E.; Couhert, A.; Guillot, A.; Desai, S.; Bonekamp, H.; Figa, J.; et al. Jason-3 Products Handbook. 2016. Available online: https://www.aviso. altimetry.fr/fileadmin/documents/data/tools/hdbk_j3.pdf (accessed on 19 March 2018).

41. Brown, S.; Islam, T. Jason-3 GDR calibration stability enabled by the cold sky maneuvers. In Proceedings of the Ocean Surface Topography Science Team Meeting, Miami, FL, USA, 23-27 October 2017.

42. Bronner, E.; Guillot, A.; Picot, N. SARAL/Altika Products Handbook. SALP-MU-M-OP-15984-CN. 2013. Available online: https://www.aviso.altimetry.fr/fileadmin/documents/data/tools/SARAL_Altika_ products_handbook.pdf (accessed on 19 March 2018).

43. Vieira, T.; Fernandes, M.J.; Lázaro, C. Independent assessment of on-board microwave radiometer measurements in coastal zones using tropospheric delays from gnss. IEEE Trans. Geosci. Remote Sens. 2018, under review.

44. Davis, J.L.; Herring, T.A.; Shapiro, I.I.; Rogers, A.E.E.; Elgered, G. Geodesy by radio interferometry-Effects of atmospheric modeling errors on estimates of baseline length. Radio Sci. 1985, 20, 1593-1607. [CrossRef]

45. Kouba, J. Implementation and testing of the gridded vienna mapping function 1 (VMF1). J. Geod. 2008, 82, 193-205. [CrossRef]

46. Fernandes, M.J.; Pires, N.; Lazaro, C.; Nunes, A.L. Tropospheric delays from gnss for application in coastal altimetry. Adv. Space Res. 2013, 51, 1352-1368. [CrossRef]

47. Dee, D.P.; Uppala, S.M.; Simmons, A.J.; Berrisford, P.; Poli, P.; Kobayashi, S.; Andrae, U.; Balmaseda, M.A.; Balsamo, G.; Bauer, P.; et al. The era-interim reanalysis: Configuration and performance of the data assimilation system. Q. J. R. Meteorol. Soc. 2011, 137, 553-597. [CrossRef]

48. Fernandes, M.J.; Lazaro, C.; Nunes, A.L.; Pires, N.; Bastos, L.; Mendes, V.B. Gnss-derived path delay: An approach to compute the wet tropospheric correction for coastal altimetry. IEEE Geosci. Remote Sens. Lett. 2010, 7, 596-600. [CrossRef]

49. Miller, M.; Buizza, R.; Haseler, J.; Hortal, M.; Janssen, P.; Untch, A. Increased resolution in the ecmwf deterministic and ensemble prediction systems. In ECMWF Newsletter; ECMWF: Reading, UK, 2010; Volume 124, pp. 10-16.

50. Thao, S.; Eymard, L.; Obligis, E.; Picard, B. Trend and variability of the atmospheric water vapor: A mean sea level issue. J. Atmos. Ocean. Technol. 2014, 31, 1881-1901. [CrossRef]

51. eoPortal:Satellite Missions Directory, Copernicus: Sentinel-6/Jason-CS (Jason Continuity of Service) Mission. Available online: https:/ / directory.eoportal.org/web/eoportal/satellite-missions/content/-/article/jason-cs (accessed on 20 February 2018).

(C) 2018 by the authors. Licensee MDPI, Basel, Switzerland. This article is an open access article distributed under the terms and conditions of the Creative Commons Attribution (CC BY) license (http:/ / creativecommons.org/licenses/by/4.0/). 